A Lagrangian Method

For Predicting Pollutant

Dispersion in Bolinas Lagoon,

Marin County, California

GEOLOGIGAL SURVEY PROFESSIONAL PAPER 582-B 

A Lagrangian Method

For Predicting Pollutant

Dispersion in Bolinas Lagoon,

Marin County, California

By HUGO B. FISCHER

D I S P E R I O N I N S URFACE WATER

GEOLOGICAL SURVEY PROFESSIONAL PAPER 582-B

$A$ study of a tidal lagoon that relates observed dye-tracer dispersion to a numerical method for predicting pollutant dispersion

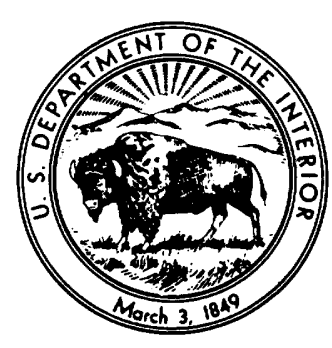

UNITED STATES, GOVERNMENT PRINTING OFFICE, WASHINGTON : 1972 


\section{UNITED STATES DEPARTMENT OF THE INTERIOR \\ ROGERS G. B. MORTON, Secretary \\ GEOLOGIGAL SURVEY \\ V. E. McKelvey, Director}

Library of Congress catalog-card No. 76-186372

For sale by the Superintendent of Documents, U.S. Government Printing Office

Washington, D.C. 20402 - Price 65 cents (paper cover)

Stock Number 2401-1213 


\section{CONTENTS}

Abstract

Introduction

Acknowledgments

Description of the numerical method

General description of the computer program

Convective step

Diffusive step

Concentration-decay step

Experiments in Bolinas Lagoon

Description of experiments

Experiment of June 18 and 19, 1968
Page

B1

1

Experiments in Bolinas Lagoon-Continued Description of experiments-Continued

Experiment of May 21 and 22, $1969 \ldots$ B8

Discussion of results _._. 8 Experiment of June 18 and 19, $1968 \ldots$ Experiment of May 21 and 22, 1969 Summary of experimental results

Numerical study of continuous discharge at the lagoon mouth - 14 Conclusions

References cited 18

\section{ILLUSTRATIONS}

Prate 1. Aerial photograph of Bolinas Lagoon at low tide on September 6, 1967

FraURE 1. Diagram showing connection of one-dimensional segments for representation of Bolinas Lagoon by the numeri-

cal program

2. Diagram showing longitudinal dispersion between adjacent elements

3-9. Graphs showing :

3. Forecast tides at mouth of Bolinas Lagoon, June 18-19, 1968

4. Observed and predicted dye concentrations at sampling sites, June 18-19, 1968

5. Forecast tides at mouth of Bolinas Lagoon, May 21-22, 1969

6. Flow velocity at the seaward end of segment 2, May 21-22, 1969

7. Predicted and observed dye concentrations at the seaward end of segment 2, May 21-22, 1969

8. Predicted and observed longitudinal distributions of dye concentration along the axes of segments 2 , 4, and 5 at approximately 1640 hours on May 21, 1910 hours on May 21, and 0640 hours on May 22, 1969

9. Observed and predicted dye concentrations at two sampling sites, June 18-19, 1968, showing effects of changing the mass-transport coefficient in the numerical program

10. Maps showing numerically predicted concentrations resulting from a constant-rate discharge at the lagoon mouth, after 10 repetitions of the tidal cycle of May 21-22, 1969

11. Maps showing numerically predicted concentrations resulting from an interrupted constant-rate discharge at the lagoon mouth, after 10 repetitions of the tidal cycle of May 21-22, 1969

\section{TABLES}

TABLE 1. Annotated flow chart of the computer program

2. Fortran listing of computer program for CDC 6400 computer 



\title{
A LAGRANGIAN METHOD FOR PREDICTING POLLUTANT DISPERSION IN BOLINAS LAGOON, MARIN COUNTY, CALIFORNIA
}

\author{
By Hugo B. Fischer
}

\begin{abstract}
A numerical method is described which is capable of predicting the movement and dispersion of a pollutant in a tidal embayment. To use the method requires a knowledge of the embayment geometry and of a typical tidal cycle of watersurface elevations at various interior points. The embayment may be segmented into a two-dimensional pattern, although how within each segment is considered to be one dimensional. Each time increment includes a convective step, a diffusive step, and a concentration-decay step. Unlike some previous numerical methods, the convective step is contrived to minimize numerical dispersion. The computer program will generate the motion and dispersion of a concentrated slug of pollutant, or it will predict the concentration of pollutant at all points within the embayment resulting from a constant discharge at one point.

The method is verified by predicting the dispersion of a slug of pollutant discharged near the mouth of Bolinas Lagoon, Calif. Bolinas Lagoon is typical of many tidal embayments in that, while it includes a number of branching eroded channels, most of its interior consists of mudflats which are exposed at low tide and shallowly covered at high tide. A field experiment is described in which a slug of Rhodamine WT dye tracer disperses in reasonable conformity to the numerical prediction.

The numerical method is used to predict the concentration distribution in Bolinas Lagoon resulting from a continuous addition of a pollutant at the location of the existing sewage outfall. A study is also made of the benefit resulting from detention of the pollutant during a 2-hour period at low tide. In this case a significant concentration reduction is observed in those parts of the lagoon which were previously the most seriously polluted.
\end{abstract}

\section{INTRODUCTION}

Bolinas Lagoon, Calif., is a tidal embayment approximately 3 miles long with a single opening to the Pacific Ocean. At low tide, water lies only in welldefined channels and pools, and most of the interior is exposed. At high tide, the lagoon surface presents an expanse of water broken only by one large and one small island. The tidal prism, which is approximately 80 percent of the high-tide volume, fills and empties the lagoon each tidal cycle by flowing up and down the eroded channels. The shallow covering of mudflats at high tide and their exposure at low tide produce an ideal habitat for many kinds of bird and sea life. At one time Bolinas oysters were renowned in San Francisco restaurants, and clamming is still popular even though prohibited by health regulations during part of the year. Part of the lagoon has been purchased by the Audubon Society as a bird refuge. Of equal interest, though less well known to tourists, are a colony of seals in possession of a part of the large central island and a shark spawning ground in the northern basin.

Bolinas Lagoon, like almost all areas of open water near large urban centers, has attracted the recreationalist and summer-home owner, and with him have come the problems of pollution. Incoming tides carry the pollutants which enter the lagoon at its mouth up the lagoon channels and distribute them throughout the interior. The purpose of this report is to provide a method for estimating pollutant concentrations within the lagoon and for determining how much pollution would be reduced by proposed changes.

Previously published analytical methods for predicting pollutant dispersion were not devised to cope with the complicated geometry of an embayment such as Bolinas Lagoon. The studies of Taylor (1954) for flow in pipes, Elder (1959) for flow down an infinitely wide open channel, Fischer $(1967,1968)$ for uniform steady flow in natural streams, and Holley, Harleman, and Fischer (1970) for oscillating flow all require that the flow cross section be uniform along its length and 
constant in time. In Bolinas Lagoon the flow divides and redivides into ever-smaller channels as it penetrates the landward reaches, and the cross sections of the channels change from well defined, narrow, and shallow at low tide to wide and irregular at high tide. An analysis is required that is capable of including these wide ranges of geometry.

Two numerical methods have been published to describe pollutant dispersion in a class of two-dimensional estuaries. Thomann and Sobel (1964) divided an estuary into subareas in plan, permitting transfer of mass between subareas according to empirical masstransfer coefficients. Orlob, Sellek, Shubinski, Walsh, and Stann (1968) used a similar method in which convection is included directly and is obtained from a numerical model of the hydraulics of the estuary. In both methods complete mixing is assumed within subareas during each time step. This mixing induces a numerical dispersion dependent on the size of subarea and length of time step, which is additive to the empirical diffusion coefficients between subareas. How much of the dispersion between subareas is included in the numerical dispersion of the computer program and how much is reflected in the mass-transfer coefficients is hard to determine.

The first section of this report describes a numerical method that substantially reduces numerical dispersion. The program convects the pollutant at the mean flow velocity through a series of interconnected channels and accepts changes in channel geometry caused by changes in tidal level. The program also includes, in a diffusive step, dispersion caused primarily by the shear effect. The shear effect is the variation in velocity between different points in the flow cross section and is described in detail in the analytical studies already referenced. To use the program the bottom geometry of the embayment must be known, as well as tidal elevations throughout a typical tidal cycle at a number of interior points. The program uses this information to predict the flow velocities at all points and the distribution of concentration resulting from either a slug or continuous injection of pollutant.

Accuracy of the numerical program is described in the section "Experiments in Bolinas Lagoon." Computer-generated dye-concentration distributions were compared with the results of two dye-dispersion experiments in the lagoon. The observed and computerpredicted results are reasonably similar. The computer program was also used to predict the concentration distribution caused by a continuous input of mass at the lagoon mouth and the concentration reductions achievable by a short detention period during a part of the tidal cycle. These results are given in the section
"Numerical Study of Continuous Discharge at the Lagoon Mouth."

Although the program was written specifically to describe dispersion in Bolinas Lagoon, the input data format is such that it could be applied without change to many other embayments of similar character. It is hoped that this program will become a useful tool in pollution studies of many coastal environments.

\section{ACKNOWLEDGMENTS}

Many persons contributed to this report. The field studies were accomplished with the assistance of personnel and equipment from the Menlo Park office of the U.S. Geological Survey, with the particular aid of Mr. Loren Young, Mr. Joe Robles, and Mr. John Limerinos. In addition, the writer wishes to thank Mr. Peter Ward, Mr. M. M. Das, Mr. Larry Eronini, and Mr. Harry Nichandros, graduate students at the University of California, all of whom voluntarily participated in data collection.

Funds for computer use to test and operate the numerical program were provided by the Water Resources Center of the University of California under project WRC-165, "The Management of Surface Water Hydrologic Systems for Water Quality Control." Some of the boats used to collect data were provided without cost by members of the Bolinas Harbor Commission.

\section{DESCRIPTION OF THE NUMERICAL METHOD}

This paper describes a numerical program which simulates convection and diffusion in a tidal embayment of complicated geometry. The program is Lagrangian in concept, in that attention is fixed on the motion of identified finite elements of fluid and diffusion is permitted between the elements. Numerical dispersion, which occurs in the convective step if concentrations must be assigned to fixed points on a spatial grid, is minimized in this program because no spatial grid is established. Instead, one computes the exact location of each finite element.

The program will be described in three ways: (1) the text describes what the program does, why it does it, what its limitations are, and how it might be extended to other embayments, (2) table 1 gives a step-by-step summary of the program and its subroutines, and (3) table 2 gives a Fortran listing of the program itself.

\section{GENERAL DESCRIPTION OF THE COMPUTER PROGRAM}

The numerical program is intended to describe the convection, dispersion, and decay of a pollutant which has been released, either continuously from a fixed 
source or as an instantaneous slug, into a tidal embayment. Flow in the embayment has the following characteristics: (1) It is not one dimensional in the sense used by Harleman (1954), Pritchard (1958), Bowden (1963), and others, because the flow branches into a number of intertwining channels. Within each of the many channels, however, the program treats the flow as being one dimensional along that channel's axis. (2) The tidal prism forms a substantial part of the total volume of the embayment at high tide, so that the flow geometry undergoes substantial change between low and high tide. To use the program, it is necessary to know the bottom geometry of the embayment and the tidal stage throughout the tidal cycle in each channel.

Using maps, aerial photographs, and as much personal familiarity as possible, the program user begins by dividing the embayment into separate channels and each channel into segments. The channel segment, a basic division required for the program, is defined as a reach of channel throughout which the cross-sectional geometry and depth of flow are at all times approximately uniform, that is a reach of prismatic channel flowing at uniform depth. Flow occurs forward or backward in the direction of the segment axis and into or out of the segment ends, and the total volume of water contained in the segment increases or decreases as the tide floods or ebbs. The length of the segment is fixed, however, and neither flow nor diffusive mass transport is permitted across the segment sides. Each segment is connected to one segment in the seaward direction (towards the mouth of the embayment) and to as many segments as desired in the landward direction. As an example, the division of Bolinas Lagoon into segments is shown on plate 1 and in figure 1.

The water contained within each segment is divided along the segment axis into volume elements. A volume element is a coherent volume of water having a uniform concentration of pollutant and filling the segment cross section. Its length, along the segment axis, equals its volume divided by the area of the cross section. How these elements are moved along the segment axis and between segments will be described in the section "Convective Step."

Each time step of the program consists of three parts: a convective step, in which volume elements are moved within the embayment at the mean flow velocity; a diffusive step, in which mass transfer occurs between adjacent elements; and a decay step, in which a first-order decay is simulated. Before the initial step, the concentrations of all the initial elements are read as input data. To simulate dispersion of a slug of pollutant, a high concentration is read into one element and zero concentration into all others. Between time steps, an additional mass of pollutant can be added to the element at any desired point within the embayment to simulate a constant rate of discharge.

\section{CONVECTIVE STEP}

The purpose of the convective step is to move each finite volume of water along its segment a distance given by the mean flow velocity in the segment multi-

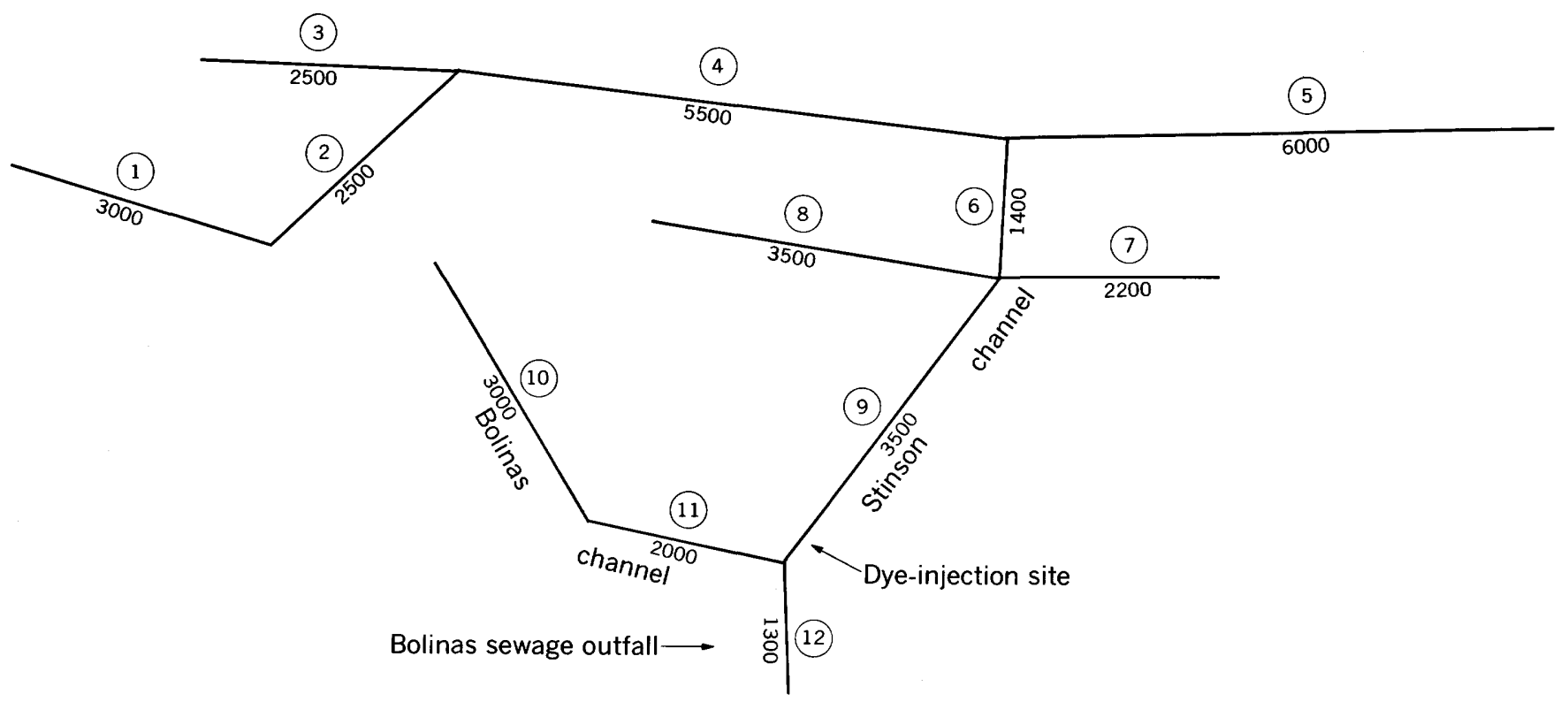

Figure 1.-Connection of one-dimensional segments for representation of Bolinas Lagoon in the numerical program. Numbers not enclosed in circles are segment lengths, in feet. 
plied by the duration of the time step. This can be accomplished by knowing the entering and exiting discharges and the cross-sectional area for each segment.

The scheme is initiated at low tide by dividing each segment into a desired number of volume elements spaced evenly along the segment axis. The discharge into or out of the landward end of each segment is computed by the change of volume of all those segments connected landward of the segment under consideration, less the fresh-water discharge, if any. Discharge is taken as being positive in the landward direction and negative in the seaward direction.

Each segment is considered in turn, beginning with segment 1, the most upstream segment, and proceeding to the highest numbered segment at the lagoon mouth. The discharge through the seaward end is found by the formula

$$
q_{i}=q_{o}+V_{t+1}-V_{t},
$$

in which $q_{i}$ is the volume of water transported through the seaward end during the time step, $q_{0}$ is the volume transported through the landward end, $V_{t+1}$ is the volume in the segment at the end of the time step, and $V_{t}$ is the volume in the segment at the beginning of the time step. Note that $q_{i}$ and $q_{o}$ are volumes, not discharges, so that the duration of the time step is not included in equation 1. The segment volumes at the beginning and end of each step, $V_{t}$ and $V_{t+1}$, must be given as input data; these data can either be measured in the field or be obtained from a hydrodynamic program such as the method-of-characteristics program given by Lai (1967). For segments which are landward ends of the embayment (segments 1, 3, 5, 7, 8 and 10 in fig. 1), $q_{o}$ is minus the fresh-water inflow, if any. Fresh-water inflow is not permitted into segments which are connected to further landward segments; for these, $q_{o}$ of the segment being considered is equal to the sum of $q_{i}$ for the landward-connected segments. For instance, for the system shown in figure 2,

$$
\begin{gathered}
q_{0}=q_{i}+q_{i}+q_{i}, \text { and } \\
q_{i}=q_{0}+V_{\theta+1}-V_{t} ;
\end{gathered}
$$

however, $q_{o}=$ fresh-water inflow into landward end of segment 1 . Note that the segment numbering system must be arranged so that the $q_{i}$ for the landwardconnected segments have been computed in advance of computing $q_{o}$ for the segment under consideration. This can be accomplished by ordering the segments, with lowest order (segment 1) corresponding to the most landward segment and segment numbers always increasing seaward. If one wished to consider a braided estuary in which one landward segment was connected to two seaward segments, the program would have to be modified.

The convection which takes place during each time step is accomplished by moving volume elements between segments. At the beginning of the time step each segment contains NMAX volume elements identified by the subscripts $m$ and $n$, where $m$ is the number of the segment and $n$ is the number of the volume element in the segment (NMAX is different for each segment), $V_{m, 1}$ is the volume of the element at the landward end of the segment, and $v_{m, n}$ is the volume element at the seaward end of the segment. Consider first what occurs at the seaward end of a given segment. Two cases must be distinguished; either the discharge is into the seaward end (positive) or out of the seaward end (negative). If the discharge is into the seaward end, a new volume element labeled $v_{m, n+1}$ is added to the segment of volume $q_{i}$. The number of volume elements which the segment contains is increased by one. If the discharge is out of the seaward end of the segcent, that is $q_{i}$ is negative, the seaward volume element, labeled $v_{m, n}$, is reduced by the amount of the outflow volume. If the endmost element, $v_{m, n}$, is not large enough to supply the entire outflow, it is eliminated entirely, and the further outflow is taken from $v_{m, n-1}$; in that case, the total number of volume elements within the segment is reduced by one. If insufficient volume is available in the combination of $v_{m, n}$ and $v_{m n-1}$, volume is taken from $v_{m, n-2}$, and this procedure continues until sufficient volume is provided. The only restriction is that during a single time step no more volume can flow out of either end of a segment than exists in the segment at the start of the step. If this does happen, the program stops, and a shorter time step must be used.

A similar procedure is used for flow through the landward end. If flow is into the landward end, that is $q_{o}$ is negative, a new element is added whose volume, $v_{m, 1}$, is equal to the flow into the segment. The identification of each of the remaining elements in the segment is increased by one, that is $v_{m, 1}$ becomes $v_{m, 2}$, and so on, and the total number of volume elements in the segment is increased by one. If flow is out of the landward end, that is $q_{o}$ is positive, the volume which flows out is taken first from $v_{m, 1}$, and if that is not sufficient, from $v_{m, 2}$, and so on. If, for instance, the outflow requires all of $v_{m, 1}$, and part of $v_{m, 2}$, the remaining portion of $v_{m, 2}$ becomes $v_{m, 1}, v_{m, 3}$, becomes $v_{m, 2}$, and so on, and the total number of elements is reduced by 1 .

In addition to storing the volumes $v_{1,1}$ through $v_{m, n}$, the computer stores the concentration of mass contained in each volume, $c_{1,1}$ through $c_{m, n}$, and the 


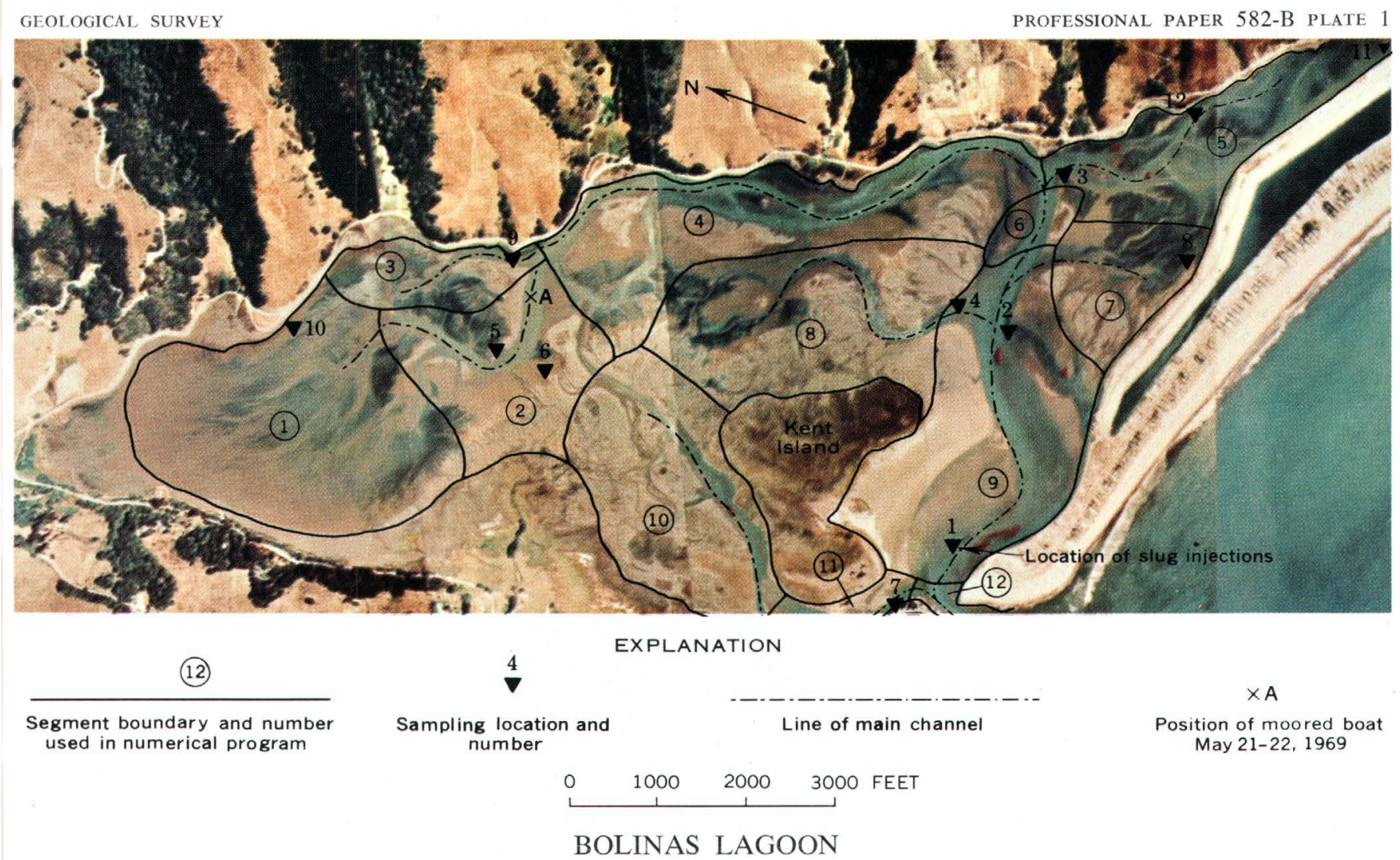

Aerial view at low tide on September 6, 1967. The red spots are dye injected by helicopter (Ritter, 1969). 
number of elements in each segment. When volume elements are moved between segments, the concentrations attached to the elements are moved also. For instance, if an outflow occurs from segment 1 to segment 2 , the concentration of the outflow becomes the concentration of the newly established element in segment 2 , that is $c_{2,1}$. If two segments converge to provide flow into a third segment, for instance segments 2 and 3 flow into 4 in figure 1 , the concentrations of the flow coming from segments 2 and 3 would be combined in forming the new element in segment 4 , such that the total mass carried by the flow was conserved.

The concentration of the outflow of a segment must be calculated from the concentrations of the elements participating in the outflow. If all the outflow can be taken from the endmost element in the segment, the concentration of the outflow equals that of the endmost element. If more volume is carried out of the segment than is contained in the endmost element, the outflow concentration must be calculated by the conservationof-mass equation,

$$
c_{o}=\frac{c_{1} v_{1}+\cdots+c_{q} v_{q}}{q_{o}}
$$

in which $v_{1}$ through $v_{q-1}$ are the volumes of elements which are carried out in their entirety, beginning with the outermost element and working inward, $c_{1}$ through $c_{q-1}$ are the concentrations of those elements respectively, $c_{q}$ is the concentration of the next inwardmost volume element, and

$$
v_{q}=q_{o}-\left(v_{1}+\cdots+v_{q-1}\right) .
$$

Note that equation 3 does present one source for $\mathrm{nu}$ merical mixing because concentrations of several volume elements are combined into one.

This completes the description of the convective step. Neither the physical location of any of the volume elements nor the velocity at which they have moved has been computed. Nevertheless, the procedure just described has accomplished what was proposed at the outset of this section, namely the convection of each volume element at the mean flow velocity of the segment in which it is located. If no diffusion between volume elements were considered, the concentrations established in the volume elements at the outset of the program would be convected up and down the embayment according to the tidal velocities, the only possibility for numerical dispersion being at the connecting points between segments.

\section{DIFFUSIVE STEP}

Longitudinal dispersion, which occurs between elements as they move along the channels, is caused pri- marily by the difference in streamwise velocity between different points on the cross section. While the elements are convected at the mean flow velocity, some individual water particles move faster than the mean and some slower. Particles in the deeper, faster moving sections are convected from one element to the one ahead, while particles in the slower moving zones near the channel banks may lag behind and be moved from the element they are in to the one behind. The result is dispersion by what is referred to as the shear effect.

Analytic studies of the shear effect, which seek methods to predict the rate of longitudinal dispersion, were referenced in the introduction. These studies give methods for predicting dispersion coefficients, which relate the rate of mass transfer through a cross-sectional surface to the local concentration gradient. The dispersion coefficients given by these studies are for asymptotically long times; that is, the flow must remain steady for a sufficiently long time before the dispersion coefficient applies. For the typical cross section in Bolinas Lagoon, a sufficiently long time is on the order of many tidal cycles; hence, the flow does not remain steady, and the cross section does not remain constant long enough for the results of the analytic studies to apply.

The simplest model of a diffusive process assumes that the transfer of mass between adjacent elements is proportional to the difference in concentration between them. The purpose of this section is to provide a way of estimating the constant of proportionality. Consider two adjacent equal-length elements as they move along a channel, and suppose that during a time step they happen to move a distance exactly equal to their own length. Figure $2 A$ shows the boundaries of the element at the beginning of the time step, and figure $2 B$ shows them at the end of the time step. The assumption embodied in the numerical program is that the boun-
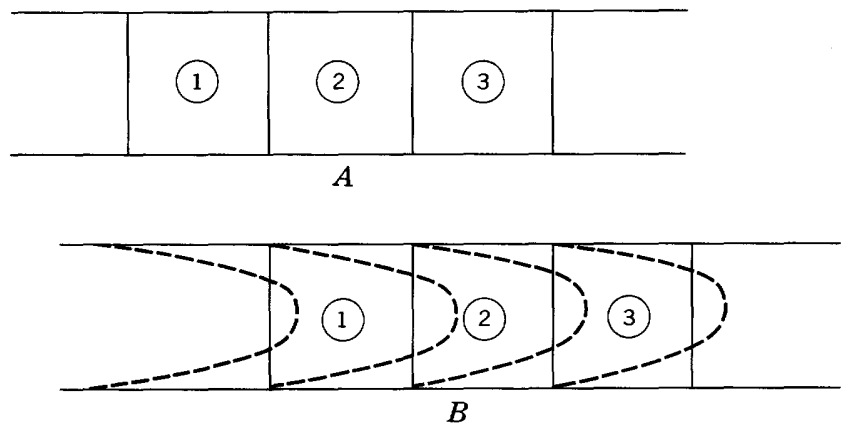

Frgure 2.-Longitudinal dispersion between adjacent elements. $A$, Position of elements at beginning of time step. $B$, Position of element boundaries at end of time step (solid lines) and position of interface between fluid particles in original elements (dashed lines). 
daries between elements are always normal to the channel axis. If, however, at the beginning of the time step one could dye all the water particles in element 1 blue and all the particles in element 2 red, the boundaries between the blue and the red spots at the end of the time step would be approximately those shown by the dashed lines in figure $2 B$. The water particles which began the time step in element 2 , but were in slow moving water near the banks, will lag behind the element and will be in element 1 ; similarly, some of the faster moving particles in element 1 will have moved ahead into element 2 . One can estimate from the figure that approximately 20 percent of the water particles will have exchanged elements.

At the conclusion of the time step the assumption required by the one dimensionality of the model is that each element becomes fully mixed; that is, the particles which enter element 2 from element 1 become evenly distributed over element 2 . Although this assumption is inaccurate, it could only be eliminated by establishing a two-dimensional mesh for each segment. Such a program was written as part of this study, but its operation for the entire lagoon would have cost far more than the funds allocated to the project. Keeping within the one-dimensional approximation and considering transport between the two equal-length adjacent elements shown in figure 3, the adjustment in concentration in each element to account for mass transport between the two is given by,

$$
\begin{gathered}
c_{t^{+}+1}=c_{1}+E\left(c_{t_{t}}-c_{1}\right) \text { and } \\
c_{t_{t+1}}^{c_{t}}=c_{{ }^{2}}+E\left(c_{t_{t}}-c_{{ }^{2}}\right),
\end{gathered}
$$

in which $c$ is the concentration in element 1 at the beginning of the time step, $c$ is the concentration in element 1 at the beginning of the time step, and so forth. $E$ is the mass-transport coefficient, a constant which can be supplied as input data to the computer program. Equations 4 and 5 describe the mass transport across one face of each element. For an element exchanging mass with elements on both sides, two faces must be considered, for instance

$$
c_{t^{+1}}=c_{2}+E\left(c_{t}-c_{2}\right)+E\left(c_{t}-c_{t}\right) .
$$

Figure 2 suggests that $E$ should have a value of approximately 0.2 .

Normally the lengths and volumes of adjacent elements will not be equal, and no element is likely to move a distance exactly equal to its own length. If the distance traveled by an element during the time step is less than its length, the mass transported across the boundary will be reduced because the distance traveled by the dashed boundary in figure 3 will be less; similarly, if the distance traveled is more than the element's length, the mass transport will be increased. For want of a more exact description, this effect has been represented in the computer program by a linear relationship; the mass-transport coefficient is adjusted as follows:

$$
E^{\prime}=E \frac{T}{x_{e}},
$$

in which $E^{\prime}$ is the adjusted mass-transfer coefficient, $T$ is the distance traveled by the shorter element during the time step, and $x_{e_{8}}$ is the length of the shorter element of the pair being considered.

A second adjustment to the transfer coefficient, perhaps more difficult to justify analytically but essential to properly represent the physical phenomenon, depends on the ratio of element length to segment width (or element width, which is the same thing). If the element is much longer than wide and if it moves a distance equal to its own length, cross-sectional mixing may be sufficient to reduce the rate of longitudinal dispersion, because a water particle originally in a low velocity zone of flow may have time to migrate into a high velocity zone, or vice versa. A particle originating in the low velocity zone of element 2 may at first lag behind the mean flow and fall into element 1 , but then migrate into the higher velocity zone and again pass into element 2 . The narrower the element, relative to its length, the more of this mixing will occur because the high and low velocity zones are relatively closer together. On the other hand, if the element width is much greater than its length little mixing can occur across the width of the cross section, so mass transport through the boundary is increased. Again, for lack of a better relationship, the effect is considered to be linear and the masstransport coefficient is adjusted by the ratio

$$
\begin{aligned}
E^{\prime \prime} & =E^{\prime} \frac{B}{x_{e}} \\
& =E \frac{B T}{x_{e}{ }^{2}},
\end{aligned}
$$

in which $B$ is the segment width.

Numerical stability requires that $E^{\prime \prime}$ always be less than 0.5. If equation 8 gives a value of $E^{\prime \prime}$ greater than 0.5 , the value is arbitrarily reduced to 0.5 .

For each segment the program considers each adjacent pair of elements in turn, first selecting the shorter element for use in equation 8 . In effect, the transfer is assumed to occur between the shorter element and its equivalent length within the longer element; then the mass transported into the longer element is distributed uniformly therein. The other pos- 
sibility, basing the transfer on the longer element, is not workable because shrinking the mass transported into the shorter element might result in a higher concentration than previously existed in either element separately. The equations used in the diffusive step are, for the shorter element,

$$
c_{t^{+1}}=c_{s}+E^{\prime \prime}\left(c_{l}-c_{t}\right)
$$

and, for the longer element,

$$
c_{l+1}=c_{l}+E^{\prime \prime}\left(c_{s}-c_{t}\right) \frac{x_{t}}{x_{e}},
$$

in which the subscript $l$ refers to the longer and $s$ to the shorter element. These equations are carried out for each pair of elements in each segment. No diffusion is permitted between end elements of adjacent segments because the increased programming complication did not seem justified by the minor increase in accuracy.

Operation of the program to simulate the experiments described in the next section showed that one further modification was necessary to correctly simulate the diffusive process. At times of low flow, particularly in the terminal segments, it often happens that a number of short elements are generated at the ends of a segment. Since the transfer coefficient between these elements must be restricted, to preserve numerical stability to a value of 0.5 the rate of longitudinal diffusion is incorrectly restrained. The probem is solved, albeit at the expense of generating some numerical mixing, by including in the program the possibility of combining adjacent short elements to form longer ones. This occurs if either of two triggering conditions are met: if the number of elements in the segment is greater than 10 and the average element length is less than one-third the segment width, or if the combined length of the two endmost elements at either end of the segment is less than the average element length within that segment. For either condition the shortest element in the segment is combined with the shorter of the two adjacent elements to form a single new element whose volume equals that of the previous two and whose concentration is the weighted average of the previous two. The element combination, when required, is made after the convective step but before the diffusive step; after the combination, the program loops back and tests whether another element combination in the same segment is required. The diffusive step is not carried out until the triggering conditions for element combination are not present.

\section{CONCENTRATION-DECAY STEP}

Each time step concludes by simulating a first-order decay of concentration. The concentration of each element is reduced by a fixed percentage determined by the rate constant of the process. For instance, if one wishes to simulate the decay of biochemical oxygen demand (BOD) with a rate constant of 0.1 per day and if the time step is 15 minutes long, the concentration in each element at the end of each time step should be multiplied by the factor 0.99762 . This factor is read into the program as input data and is used to reduce the concentration at the end of each time step.

\section{EXPERIMENTS IN BOLINAS LAGOON DESCRIPTION OF EXPERIMENTS}

The computer program can be used to study the dispersion of a slug of pollutant injected as an instantaneous source, or it can determine the distribution of concentration caused by a steady source. Practical concern is usually with a steady, or quasi-steady, source, such as a sewage outfall. Correct operation of the program, however, is more easily observed by study of the dispersion of a slug injection, because both the movement of the mean location of the slug and its dispersion around the mean are more easily measured. Moreover, if the program can be verified for the dispersion of a slug, it can be used with confidence to study the distribution from a constant-rate injection, because a constant-rate injection is the sum of a series of slug injections. The two field experiments designed to test the computer program were both slug injections at the mouth of Bolinas Lagoon. Both injections were made at the point indicated on plate 1 , the first at approximately 1400 hours on June 18, 1968, and the second at 1345 hours on May 21, 1969. The major difference between the experiments was the type of tide, as described in the following sections.

\section{EXPERIMENT OF JUNE 18 AND 19, 1968}

Forecast tides at the mouth of Bolinas Lagoon for June 18-19, 1968, are shown in figure 3. On June 18, low slack water occurred at the injection site between 1300 and 1315 hours. The plan was to inject the tracer slug, 161/2 gallons of Rhodamine WT fluorescent dye, as rapidly as possible across the channel cross section at 1345 hours. The drum of dye was carried in a rowboat towed behind a larger boat intended for use later for sampling. The dye drum and two operators proved more than a safe load for the rowboat, and the hose provided to drain the tank was too small to carry a sufficient flow for even an approximately instantaneous injection. Although the injection began on schedule at 1345 hours, only approximately half the tank was 


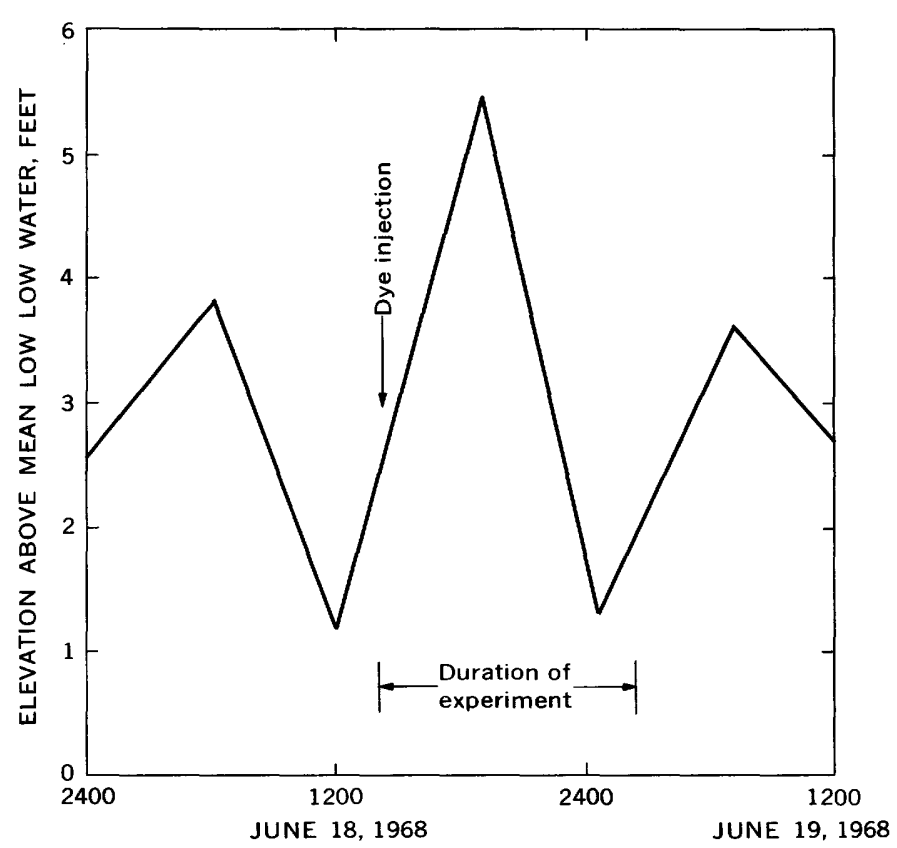

Figure 3.-Forecast tides at mouth of Bolinas Lagoon, June 18-19, 1968

drained at 1410 hours. The tank was then light enough to be upended, and the remainder of the contents was emptied within several minutes.

Before the dye injection, standard concentration samples were prepared at the experiment site by diluting known concentrations of dye with sea water taken from the mouth of the lagoon. The standard samples had concentrations of $0.5,1.0,1.25,2.5,5.0$, $10.0,12.5,25$, and $50 \mu \mathrm{g} / 1$ (micrograms per liter). The bottles containing the standards were handled in exactly the same way as all sample bottles taken from the lagoon during the experiment, so that any physical or chemical reactions which might occur to the dye in the collected samples would also occur in the standards of known concentration. After the experiment, all bottles containing both samples and standards were taken to the hydraulics laboratory of the University of California, Berkeley, where they were analyzed on June 21, 1968, for fluorescence by using a Turner model 111 fluorometer. The calibration of the fluorometer by the standard samples was found to be linear in all cases.

During the experiment, samples were obtained by four parties, three in boats and one on shore. A total of 12 sites was to be sampled approximately every half hour during a 12-hour period. Each boat party attempted to sample two or three sites, while the shore party repeatedly circled the lagoon taking samples at five shore sites. The sampling sites are shown on plate 1 ; sites $1,2,3,4$, and 5 were marked by buoys, lighted at night. Site 7 was off a pier at the town of Bolinas and was sampled from the pier during periods of high tide. Site 6 was intended to be over the mudflats in shallow water approximately even with site 5 . At night, the sampling party had difficulty orienting itself to site 5 and determining where to sample. Site 3 was abandoned after dark when the sampling party was unable to navigate between sites 2 and 3 without running aground repeatedly on mudflats. Thus continuous and reliable concentration records were obtained only at sites $1,2,4,5$, and 7 and the shore-sampled sites 8 through 12. Whenever possible, the samples from shore were obtained by wading into water at least 2 feet deep. At site 10, however, the sampler often sank into the mud and was forced to obtain the sample just at water's edge. Sampling was continuous in most cases until 0200 hours on June 19. At points 1 and 7, sampling was continued until 0800 hours to determine how much of the dye carried out to sea during the ebb was returned on the following flood.

\section{EXPERIMENT OF MAY 21 AND 22, 1969}

The experiment of May 21-22, 1969, was conducted in a manner similar to that of the experiment of June 18-19, 1968, except that only two sampling boats were available. An improved dye injector allowed the entire quantity of approximately 25 gallons of Rhodamine IVT dye to be injected in approximately 5 minutes, beginning at 1345 hours on May 21. One of the two sampling boats was moored permanently at the seaward end of segment 2 , at the point marked "A" on plate 1 ; at 15 -minute intervals samples of water from the surface were obtained, and water velocity was measured at approximately the 0.4 depth (from the bottom) beneath the boat. The other sampling boat was used to cruise up and down the lagoon, taking samples along the segment axes. A traverse beginning at the landward end of segment 2 and proceeding down segment 2 and segment 4 and up segment 5 to its landward end could be completed with a collection of 15 samples in approximately 40 minutes. The axes of segments $6,8,9,10$, and 11 were also traversed at infrequent intervals. The moving-boat procedure was a change from that of the previous experiment made for two reasons: (1) only enough personnel were available to form two sampling parties and (2) by moving one sampling boat, that party could attempt to obtain an approximately instantaneous view of the spatial distribution of dye concentration, which would compare directly with the computer output.

\section{DISCUSSION OF RESULTS}

\section{EXPERIMENT OF JUNE 18 AND 19, 1968}

The dye concentrations measured at all sampling sites during the 1968 experiment are shown in figure 4 . 

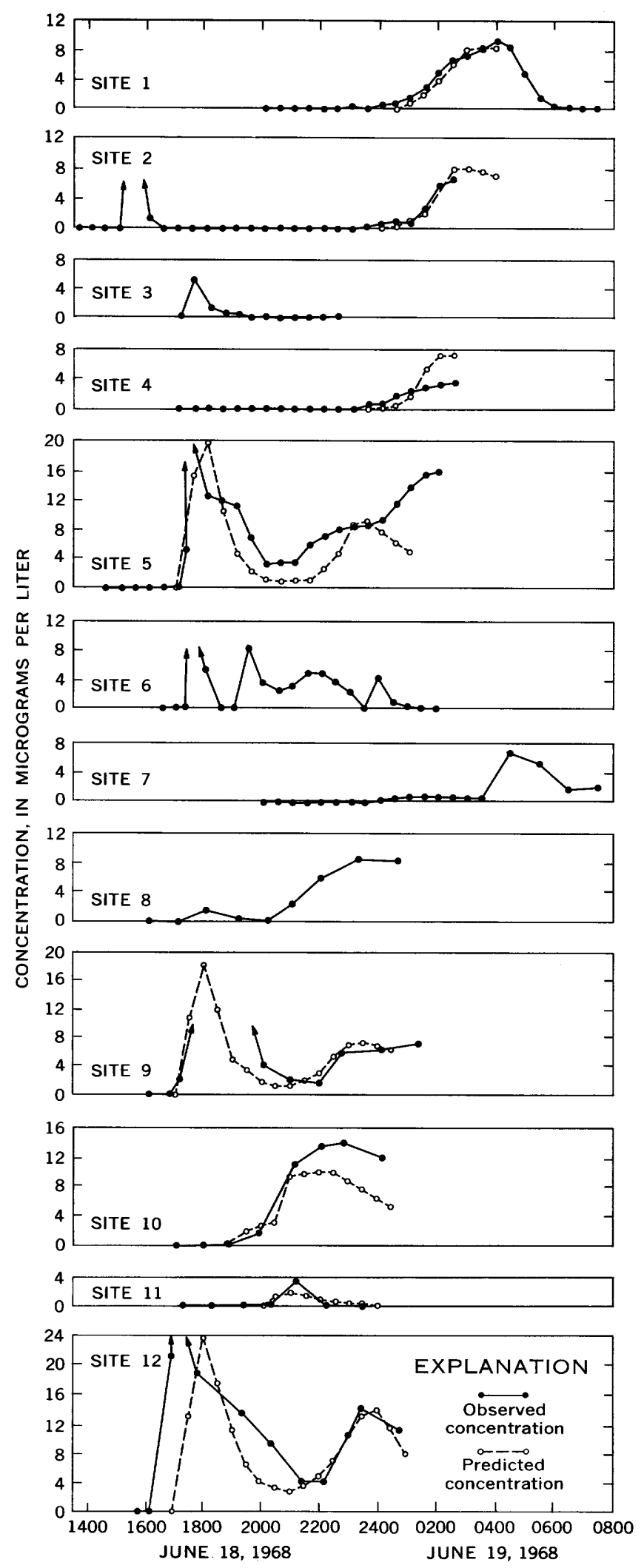

FIGURE 4.-Observed and predicted dye concentrations at sampling sites, June 18-19, 1968.
The flow, as it enters the mouth of the lagoon, forks into two channels: the northern one known as the Bolinas channel and the southern one known as the Stinson channel. The dye slug was injected only into the Stinson channel on an incoming tide so that none of the slug entered the Bolinas channel. The flow further divides at the east side of the lagoon into one channel which flows south towards Stinson Beach (at the south end of the lagoon) and one which flows north to the north end of the lagoon. The dye was carried up the Stinson channel and divided into the two channels, through which high concentrations reached the southernmost and northernmost ends of the lagoon. During tidal outflow, the dye returned from the channels along the same routes by which it went in. The dye concentration measured at station 7 showed almost no dye concentration at any time during the inflow and outflow of the first tidal cycle; thus for these tidal conditions essentially none of the dye carried up the Stinson channel crossed over and flowed out by way of the Bolinas channel.

The dashed lines in figure 4 show the concentration at the sampling points predicted by the computer program using as a mass-transport coefficient $E=0.2$. To use the program, the lagoon was segmented as described previously; widths and lengths of each segment were scaled from maps and aerial photographs, and tidal elevations were estimated from the forecast tide at the mouth. A time step of 15 minutes was adopted, and a $121 / 2$ hour period of inflow and outflow was simulated. Since tidal elevations were not actually measured during the experiment, the data used as input to the computer program are necessarily inexact; nevertheless, the comparison between computer prediction and measured concentrations at most points is quite good.

The best verification of the accuracy of the diffusive step in the computer program is the comparison of predicted and observed concentration at site 1 . By the time the dye cloud reached this point during tidal outflow, the slug had been dispersing for 12 hours. The slope of the rising limb of the slug is a measure of how much the slug has dispersed. Figure 4 shows that the measured and predicted slopes are almost exactly the same; thus dispersion has been accurately modeled.

The convective motion of the dye cloud also seems to have been accurately modeled, as shown particularly at sites 5 and 12 by the proper occurrence of the first passage of the cloud and the low concentration observed at high tide. The cloud passes each site at approximately the time and with approximately the extent predicted by the computer program. The only significant and repeated error is that during tidal out- 
flow the concentration at several sites (particularly 5 and 10) decreases more quickly in the prediction than was actually observed. It seems likely that diffusion in the northernmost basin, represented by segment 1 in the computer program, is not adequately represented.

No predictions are shown for sites $3,6,7$, and 8 . At site 3 the program predicted passage of a high peak of short duration prior to the time the first sample was obtained and predicted outflow of the cloud after sampling had been discontinued; hence no comparison of predicted and observed clouds could be made. At site 7 , the program predicted zero concentration until low tide, when the numerical program was stopped; the peak observed at site 7 at 0400 hours on June 19 was caused by tidal inflow carrying in dye which had previously flowed out to the lagoon mouth. The erratic concentrations measured at site 6 probably result from the site's location near the boundary between segments 2 and 10, one of which is fed by the Bolinas channel and the other by the Stinson channel. The sampling site was not well marked, and the sampling party probably sampled sometimes in one segment and sometimes in the other. Site 8 is also near the boundary between two segments, numbers 5 and 7 ; presumably the high concentrations observed in samples taken after 2100 hours result from water in segment 5 , whose concentration is better indicated by the measurements at site 12 .

\section{EXPERIMENT OF MAY 21, AND 22, 1969}

The major difference between the experiments of 1968 and 1969 was the type of tidal cycle. The 1968 experiment was planned to coincide with a $121 / 2$-hour symmetrical tide; that is, the tide returned to its beginning level after 121/2 hours. The 1969 experiment was conducted during a 25-hour nonsymmetrical cycle; as shown in figure 5, the tide first rose to a low high, then dropped slightly to a high low, then rose to a high high, and finally returned to approximately the beginning level. This type of tide tests more severely the approximations embodied in the computer program, because during the long period of high water significant exchange is possible across the boundaries of supposedly nonconnected segments. Also, because of different velocities of propogation of the tidal wave up the Bolinas and Stinson channels, a net circulation of water flowing up channels 4 and 8 and down channel 10 seems likely between the low high and the high low tides. This circulation is not permitted in the computer program and seems to have been a source of significant error.

Prior to the actual experiment, the tidal hydro-

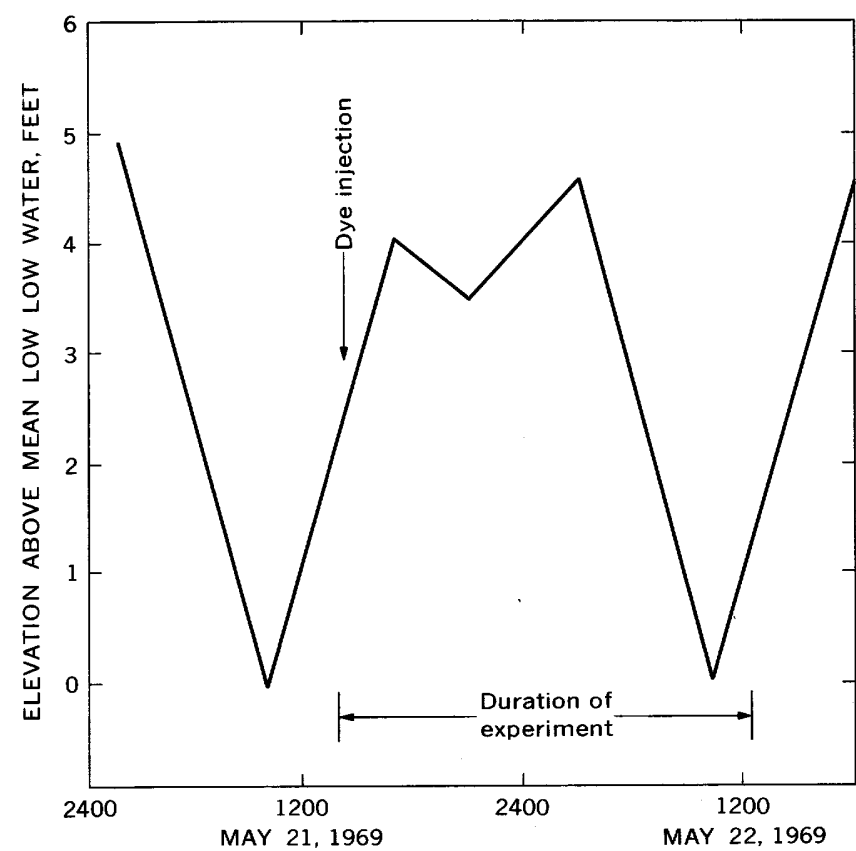

Figure 5.-Forecast tides at mouth of Bolinas Lagoon, May 21-22, 1969

dynamics of the lagoon were modeled using a segmented method-of-characteristics computer program similar to that described by Lai (1967). The hydrodynamic program, which had not been developed by the time of the 1968 experiment, did not permit flow between the Bolinas and Stinson channels, however, and so the results are somewhat in error. The hydrodynamic program predicted velocities and tidal elevations in each segment, and the resulting elevations were used as input to the dispersion program. The predicted mean velocity in the cross section at the seaward end of segment 2 is shown in figure 6 , which also shows the velocities measured beneath the moored boat. One should not expect the magnitudes to be the same, as the observed velocity does not represent a cross-sectional mean. Nevertheless, the general appearance of the two plots and the times of tidal reversal are sufficiently similar to say that the hydrodynamic program appears to be reasonably accurate.

The observed and predicted dye concentrations at the seaward end of segment 2 are shown in figure 7 . As for the previous experiment, all predictions shown for this experiment use a mass-transport coefficient of $E=0.2$. The peak concentration arrived sooner than predicted and was sharper. A partial explanation may be that the observed values are for one point in the center of the channel, whereas the prediction is of of the cross-sectional mean concentration. The sampling party reported that after passage of the peak at the boat, substantial concentrations of dye could be 


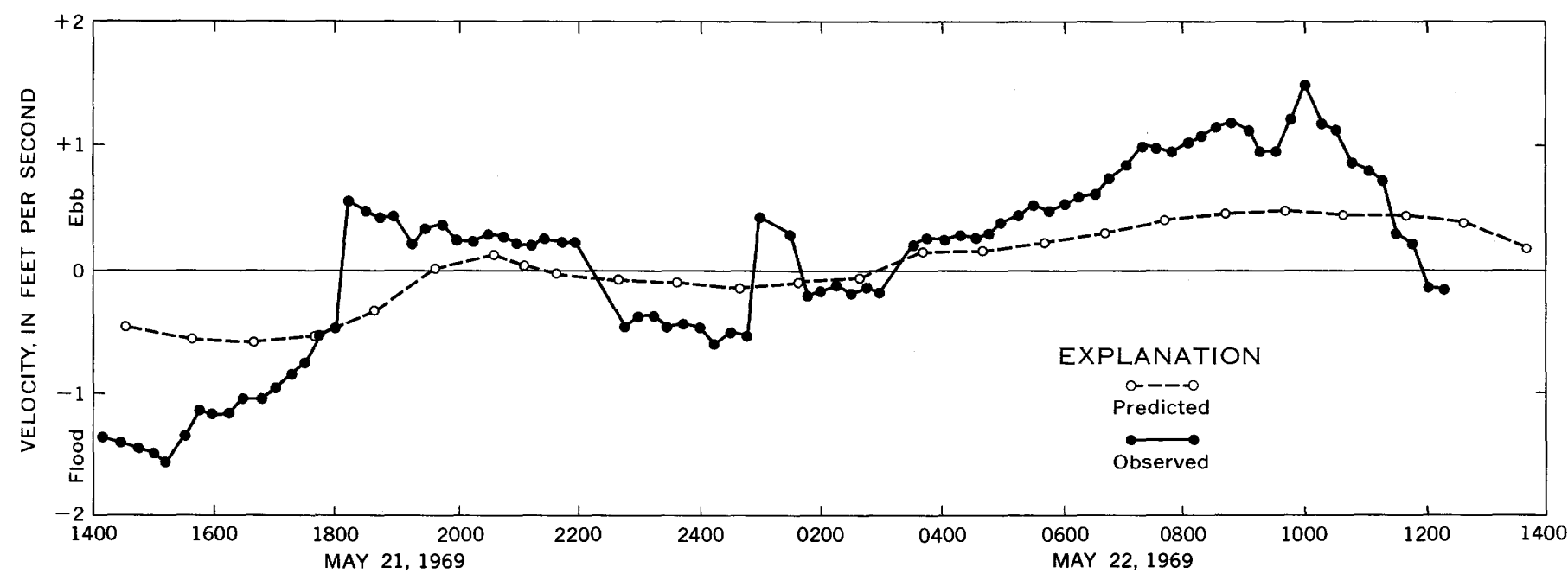

Figure 6.-Flow velocity at the seaward end of segment 2 (point A in fig. 1), May 21-22, 1969. Predicted values are crosssectional mean velocities. Observed values are velocities measured at 0.4 depth directly beneath the moored boat.

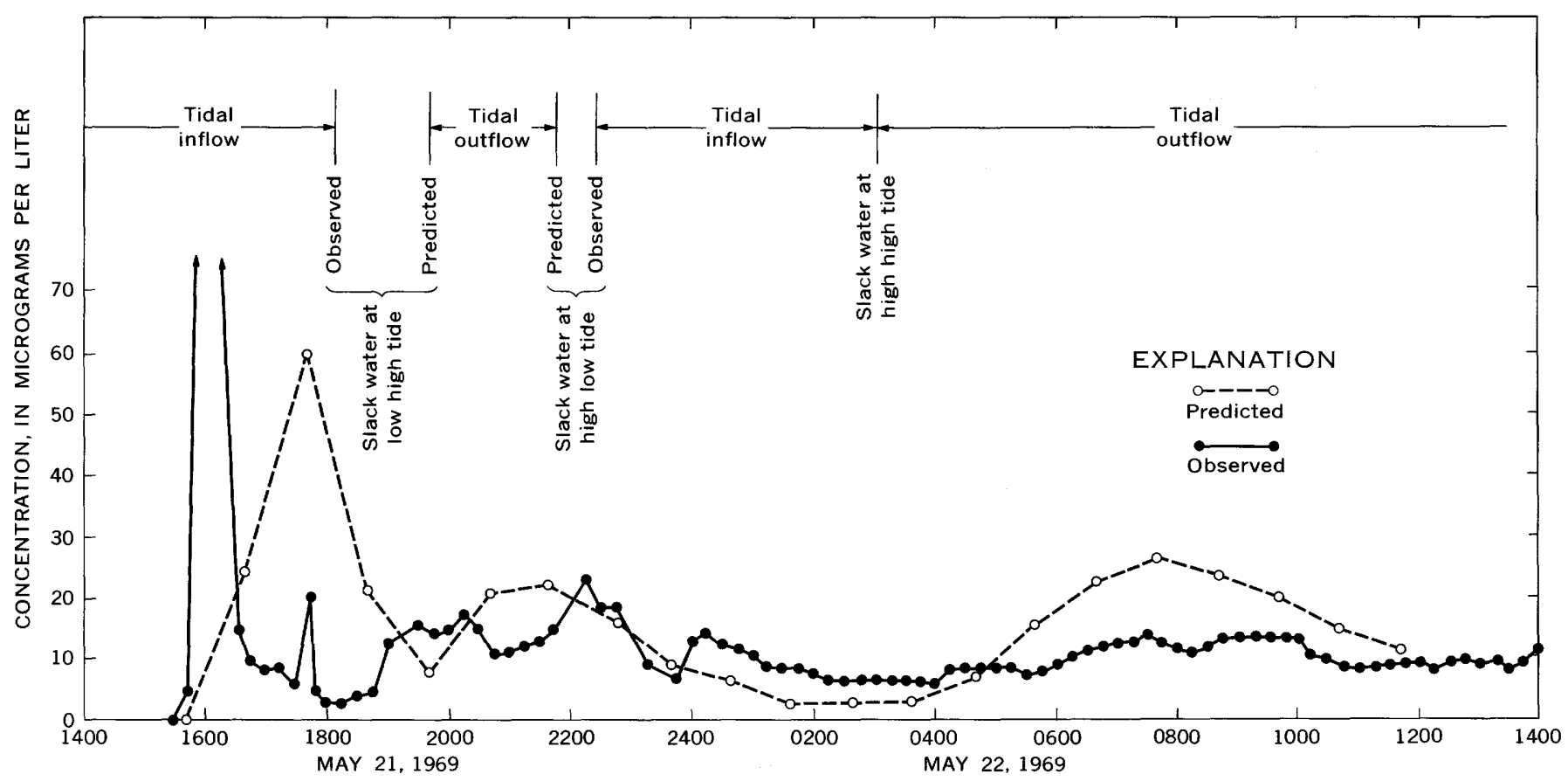

Frgure 7.-Predicted and observed dye concentrations at the seaward end of segment 2 (point A in fig. 1), May 21-22, 1969.

seen along the banks. If enough cross-sectional concentration measurements had been obtained to define the cross-sectional mean, the observed and predicted results would have been in better agreement. (Note, for instance, the comparison of the centerline and cross-sectional mean concentrations observed in the Green-Duwamish River by the writer (Fischer, 1968, p. A20, fig. 16).)

According to the prediction, the main body of the dye cloud was expected to pass point " $A$ " during the initial tidal inflow. During the partial outflow between the low high and the high low tides, some of the cloud was predicted to return to the point, so that a peak concentration would be recorded at the low slack water. During inflow to the high high tide the entire cloud was expected to be carried landward of the measuring point into segment 1 . Then, during the main tidal outflow, the entire cloud was expected to pass the observation point, with the peak concentration occurring at approximately 0730 hours on May 
22. The observed values show that the prediction was reasonably correct; the entire cloud did pass the observation point during the first inflow, and part of the cloud did return so that a peak was observed at the low slack water around 2200 hours on May 21. During the high high tide, concentrations were higher than had been anticipated, possibly because of mixing with the high concentrations expected in the landward end of segment 8 . During the main tidal outflow, a peak was observed at approximately the anticipated time, but its magnitude was much less than expected. This result agrees with that of the 1968 study, which showed that the program underestimates the rate of mixing in the northernmost basin (segment 1).

Longitudinal dye distributions along the axes of segments 2,4 , and 5 are shown in figure 8 . In agreement with figure 7 , the observed distribution shows that for the first traverse, at approximately 1640 hours on
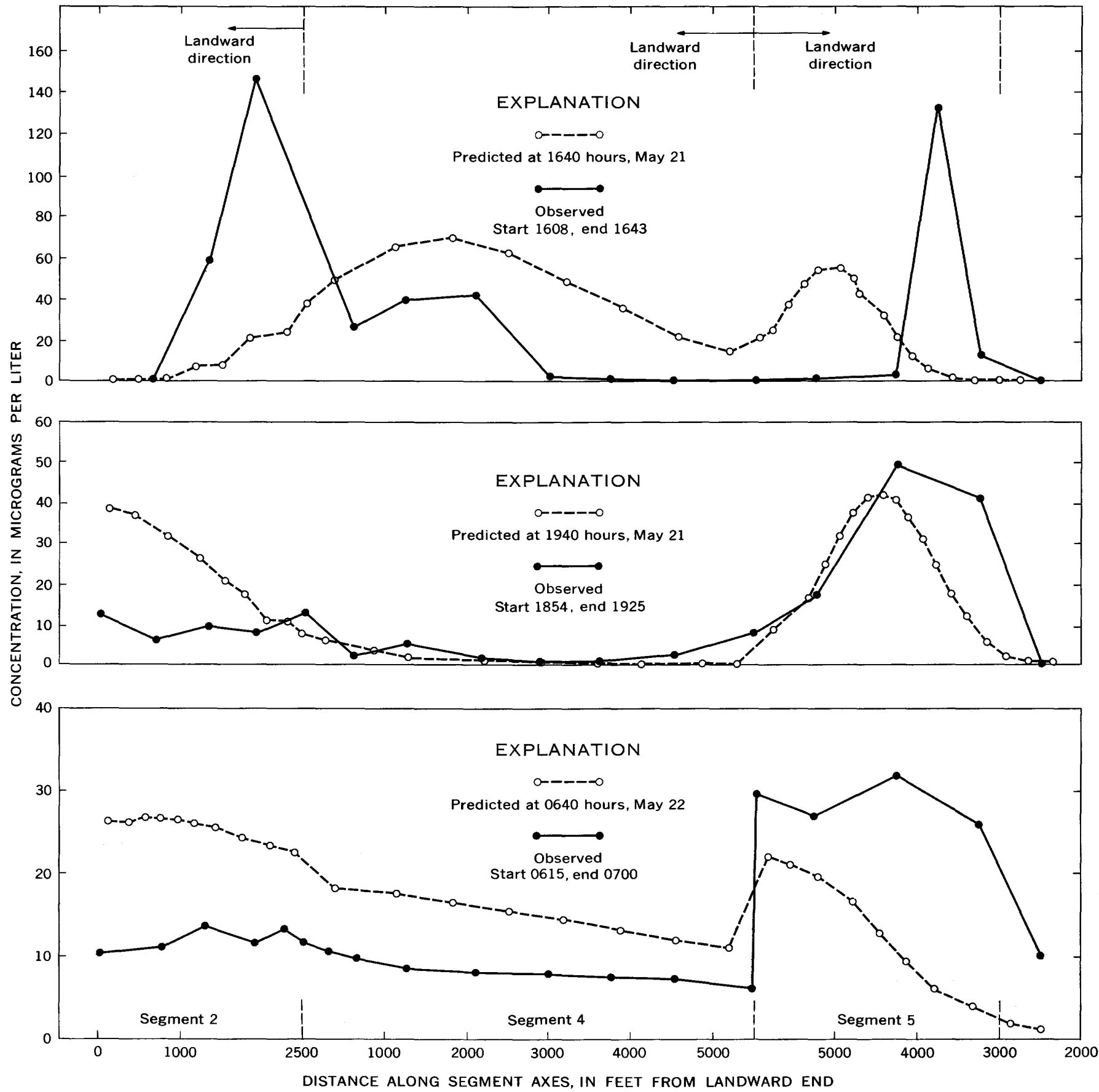

Figure 8.-Predicted and observed longitudinal distributions of dye concentration along the axes of segments 2,4 , and 5 at approximately 1640 hours on May 21, 1910 hours on May 21, and 0640 hours on May 22, 1969. 
May 21, has moved more landward than was predicted. In part, this may result from errors in the tidal hydraulics program. Also, as in figure 7, the observed samples were taken on the channel centerline, whereas the prediction is for the cross-sectional mean. Had samples been taken along the channel sides, a significantly different observed graph would have been obtained. Unfortunately, time did not permit obtaining enough samples to define the cloud completely. The second traverse, at approximately 1910 hours on May 21, shows a good agreement between prediction and observation in segment 5 ; however, the observed cloud has already passed from segment 2 into segment 1 , sooner than predicted. The third traverse, taken at approximately 0640 hours on May 22, after the beginning of the main tidal outflow, also shows reasonable agreement with the prediction in segment 5 , but in segments 2 and 4 significantly more mixing has taken place than was anticipated. In part, the low concentrations in segments 2 and 4 may result from mixing with clear water from segment 10 during the prolonged period of high water.

As mentioned previously, the dye-concentration predictions shown for both experiments (figs. 4, 7, and 8) were made using a mass-transport coefficient of $E=0.2$. Two additional predictions were made, one using $E=$ 0.0 , to observe the magnitude of the numerical dispersion, and one using $E=0.4$, to observe the effect of changing the coefficient. Figure 9 shows the results for $E=0.0$ for two sites during the experiment of June 18-19, 1968. The figure also shows, for comparison, the observed data and computer results using $E=0.2$. The figure shows that at site 5 little dispersion is observed if $E=0.0$ (if the program were perfect it would yield no dispersion at all). During both tidal inflow and outflow a high peak is observed at one of the hourly readings, and almost zero concentration is observed at all other times. During tidal outflow at site 2 , two peaks are observed: the first is from concentration stored at high tide in segment 5 and the second is from concentration from segments 1 through 4 . The different times of return of the two peaks do not reflect numerical dispersion, but are caused by different rates of convection in the different segments. Thus figure 9 shows that if the computer program is run with no dispersion intended, little dispersion results; computer-generated numerical dispersion is not significant in this program.

When the computer program was run with $E=0.4$, predictions were obtained showing somewhat, but not significantly, greater dispersion than for the runs with $E=0.2$. The difficulty resulted from the adjustment of the transport coefficient to account for element

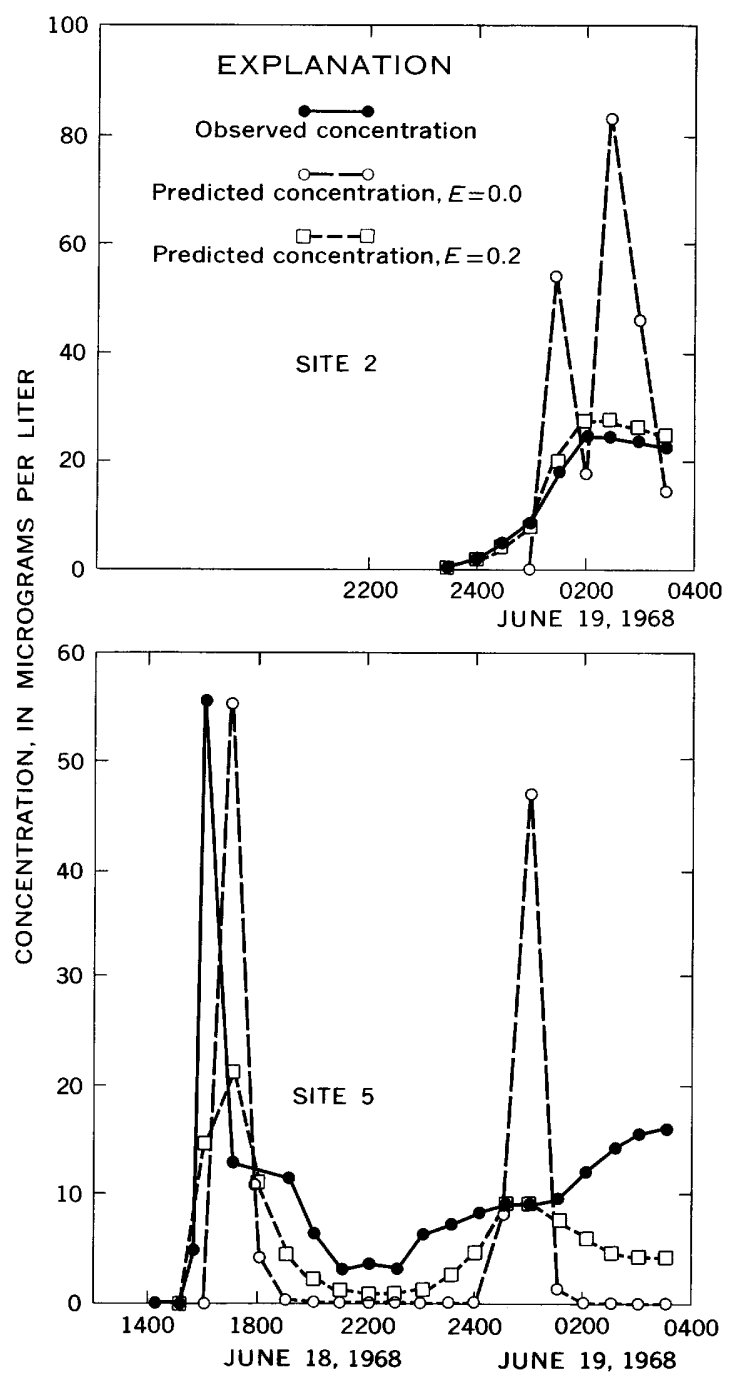

Figure 9.-Observed and predicted dye concentrations at two sampling sites, June 18-19, 1968, showing effects of changing the mass-transport coefficient in the numerical program.

travel and segment width, as given by equation 8 , and the requirement that the adjusted coefficient $E^{\prime \prime}$, not exceed 0.5 . For the runs with $E=0.2$ the adjusted coefficient did not often exceed 0.5 ; for instance, for the experiment of June 18-19, 1968, out of 3,034 computations of $E^{\prime \prime}, 716$ gave a value greater than 0.5 (24 percent). Of the remainder, 224 were greater than $0.4,338$ were between 0.3 and $0.4,391$ between 0.2 and $0.3,588$ between 0.1 and 0.2 , and 777 less than 0.1 . If the value of $E$ is doubled, however, the computed values of $E^{\prime \prime}$ also double, and many more values of $E^{\prime \prime}$ greater than 0.5 are obtained. Since all these must be reduced to 0.5 to maintain numerical stability, the rate of dispersion of the cloud is not greatly increased over that for $E=0.2$. 


\section{SUMMARY OF EXPERIMENTAL RESULTS}

Two dye-dispersion experiments were made using the same procedure in the same lagoon, but they were for tidal cycles of significantly different character. The first experiment was conducted during a symmetrical $121 / 2$ hour cycle, during which the tidal elevation at the mouth rose from a low to a high and then returned to the same low. The results showed that circulation, implying a circulatory motion of water within the interior of the lagoon, was not an apt description of the flow caused by this type of tide. Water to supply the high-tide volume entered the lagoon by flowing up the several channels. At high tide there was little motion and little mixing. Although perhaps different in small-scale detail, in gross pattern the outflow appeared to be simply the reverse of the inflow. Water flowed out through the same channels through which it flowed in.

Ritter (1969) dropped dye from a helicopter to observe motion in the lagoon during a tidal cycle similar to that of the first experiment. (Plate 1 is a photograph taken during his study and shows some of his dye patches.) The gross patterns of flow determined by Ritter and during the present experiment were similar; for instance, Ritter stated that dye deposited in the Bolinas channel did not cross over into areas apparently filled through the Stinson channel. Ritter remarked that the flow appeared to be more channelized on inflow than during outflow; if true this would not invalidate the present approach, although perhaps the appropriate values of $E$ might undergo some change. Unfortunately, Ritter's experiments did not span an entire tidal cycle, and on inflow, dye spots were placed only in the channels; so the details of the flow remain open for further study.

The second experiment was conducted during a 25hour tidal cycle in which the tide remained relatively high during the central 12 hours. While the tide remains high, changes in tidal elevation produce surges within the lagoon which appear to accomplish some net circulation between the Bolinas and Stinson channels. The computer program does not allow exchange between the two channels, and therefore the results obtained for the second experiment did not match the predictions as well as for the first experiment. Nevertheless, the results of both experiments verified the numerical predictions with reasonable accuracy. The results show that flow in the lagoon is channelized and can be segmented much as was done in the numerical analysis. Thus a flow which at first sight appears to be too complicated for analytical study can be broken into a number of isolated segments, each of which can be analyzed and the results combined.

\section{NUMERICAL STUDY OF CONTINUOUS DISCHARGE AT THE LAGOON MOUTH}

As an example of a practical use of the numerical program, a study was made of a continuous discharge of pollutant at the lagoon mouth. Two cases were studied: in one the pollutant was discharged at a constant rate throughout the tidal cycle, while in the other the discharge was interrupted during the 2 hours of lowest water during each $121 / 2$-hour period. The comparison shows how much reduction in pollutant concentration results from interruption of the pollutant outflow at low tide.

For each case the computer program was run continuously for ten 25-hour tidal cycles, using the same tidal inflow and outflow as for the slug-discharge study of May 21 and 22, 1969. The concentration of all elements inside the lagoon was initially set equal to zero, and an addition of a constant number of mass units was added to the element nearest the center of segment 12 during each 15-minute time step. The injection point corresponds approximately to the location of the existing Bolinas sewage outfall pipe. A decay factor of 0.99762 per time step was used, corresponding to a rate constant of 0.1 per day, as usually assumed for BOD. The concentration units used in this study are strictly arbitrary and have meaning only in relation to each other; no attempt has been made to relate the study to the actual amount of BOD released into the lagoon.

Figures $10 A$ and $B$ show the concentration distribution at the low high and high high tides resulting from the constant-injection study. The highest concentrations are in two areas near the south and north ends of the branches fed by the Stinson channel. The high concentrations are apparently formed at the point of injection at low tide, when the volume of water contained in the channel is small and only a small quantity of water is available for dilution. As the tide begins to flood, the water containing high concentrations is carried inland. While the incoming discharge is small, the concentration of the inflow remains high, but as the discharge increases, the input of mass at the injection point remaining constant, the concentration of the inflow is reduced. The minimum incoming concentration occurs at the point of maximum flow discharge. As the discharge decreases with approaching high tide, the concentration again increases, but not to such a high level as at low tide because more water is available for dilution.

The water containing the high concentration is convected into the lagoon, and the high concentration zone disperses as did the slug injection. At the low high tide the water which originated at the lagoon 
mouth at the low low tide has been carried almost to the ends of all the channels. Those areas which show as the highest concentrations in figure $10 \mathrm{~A}$ represent the areas to which the water at the lagoon mouth at low tide is convected during the inflow. The areas having the lowest concentration at high tide are those to which water entering the lagoon during maximum flood discharge is convected. At high tide, an area of fairly high concentration exists near the lagoon mouth, but as soon as the tide turns the water containing this concentration will flow out of the lagoon.

The concentration distribution at the high high tide (fig. 10) is complicated by areas of high concentration formed at both the low low and high low tides. The high concentrations found at the northernmost and southernmost ends of the lagoon are those originally formed at low low tide, and the peak concentrations are somewhat less than at low high tide because of dispersion in the period between highs. A new area of high concentration, formed during the high low tide, is found in the center of the lagoon.

The highest concentrations found in the Bolinas channel are significantly less than those in areas filled through the Stinson channel. During the experiments, a sandbar crossed the Bolinas channel at the point where the channel joins the lagoon mouth. The sandbar restricted flow into the Bolinas channel during periods of low tide, so that the water containing the highest concentration bypassed the Bolinas channel and flowed almost entirely up the Stinson channel. The Bolinas channel was filled with water which entered the lagoon sometime after low tide, and, hence, contained lower pollutant concentrations.

The low concentrations shown in figures $10 A$ and $B$ at the northernmost and southernmost extremes of the lagoon result from the decay factor introduced in the numerical study. If the pollutant did not decay according to the given decay factor, diffusion would raise the concentration in these extremities to the same level as exists in the adjacent zones of high concentration.

The predicted concentrations shown in figure 10 have not been verified by experiment for two reasons: first, the concentration distribution depends on the rate of decay of the pollutant, and no dye is known which decays at the same rate as BOD; and second, the distribution predicted by the computer is for a repetition of a series of identical 25-hour cycles of the tidal flow predicted for the experiment of May 21-22, 1969, whereas, in reality, the tidal heights vary. Nevertheless, visual and ecological observations verify that the distribution of pollutants in the lagoon in 1968 and 1969 was similar to that shown in the figure.
Visually, accumulations of sewage-type refuse could be observed along the shore at high tide in the areas which are shown as zones of consistently high concentration in figures $10 A$ and $B$. Ecological studies by Gustofson (1968) suggested that these zones were the least habitable to higher forms of life. Thus, although the computer program has not been verified in detail for the continuous release and indeed is based on an approximate lagoon geometry and only one of a great many possible tidal flows, the concentration distribution predicted by the program seems to be in good agreement with the distribution of pollution observed in the lagoon.

Figures $11 A$ and $B$ show the change caused by interrupting the pollutant discharge during the 2 hours of lowest tide, beginning one-half hour before low slack water and continuing until 11/2 hours after slack water. Figure $11 A$ shows the concentration distribution at the same time as figure $10 A$, and figure $11 B$ corresponds to figure $10 B$. The high concentrations evident in figures $10 A$ and $B$ have been eliminated because those concentrations were produced by the discharge during the low tide period. The comparison of figures $10 \mathrm{~A}$ and $B$ with $11 A$ and $B$ shows how much reduction in pollutant levels in the more seriously polluted areas of the lagoon might be achieved by construction of a small detention structure to withhold discharge of Bolinas sewage for relatively short periods at low tide. Again. it must be emphasized that this conclusion is based on a numerical model using approximate lagoon geometry and only one of a number of possible tidal flows. In spite of these approximations, it seems reasonable to conclude that provision of a detention structure would significantly reduce pollution problems within the lagoon.

\section{CONCLUSIONS}

The numerical program described predicts the effect of tidal inflow and outflow on the distribution of a pollutant in a tidal embayment. Use of the program requires knowledge of the embayment geometry and the tidal elevations at various interior points throughout the tidal cycle. The program models the convective motion of water within the embayment and accomplishes the convective motion of a tracer or pollutant dissolved in the water while minimizing numerical dispersion. Diffusion of the tracer between adjacent elements of water occurs during a diffusive step at a rate predicted by physical considerations of the mechanics of dispersion.

The numerical program has been verified by dyetracer experiments in two types of tidal cycle in Bolinas Lagoon, Calif. The observed motion and dis- 

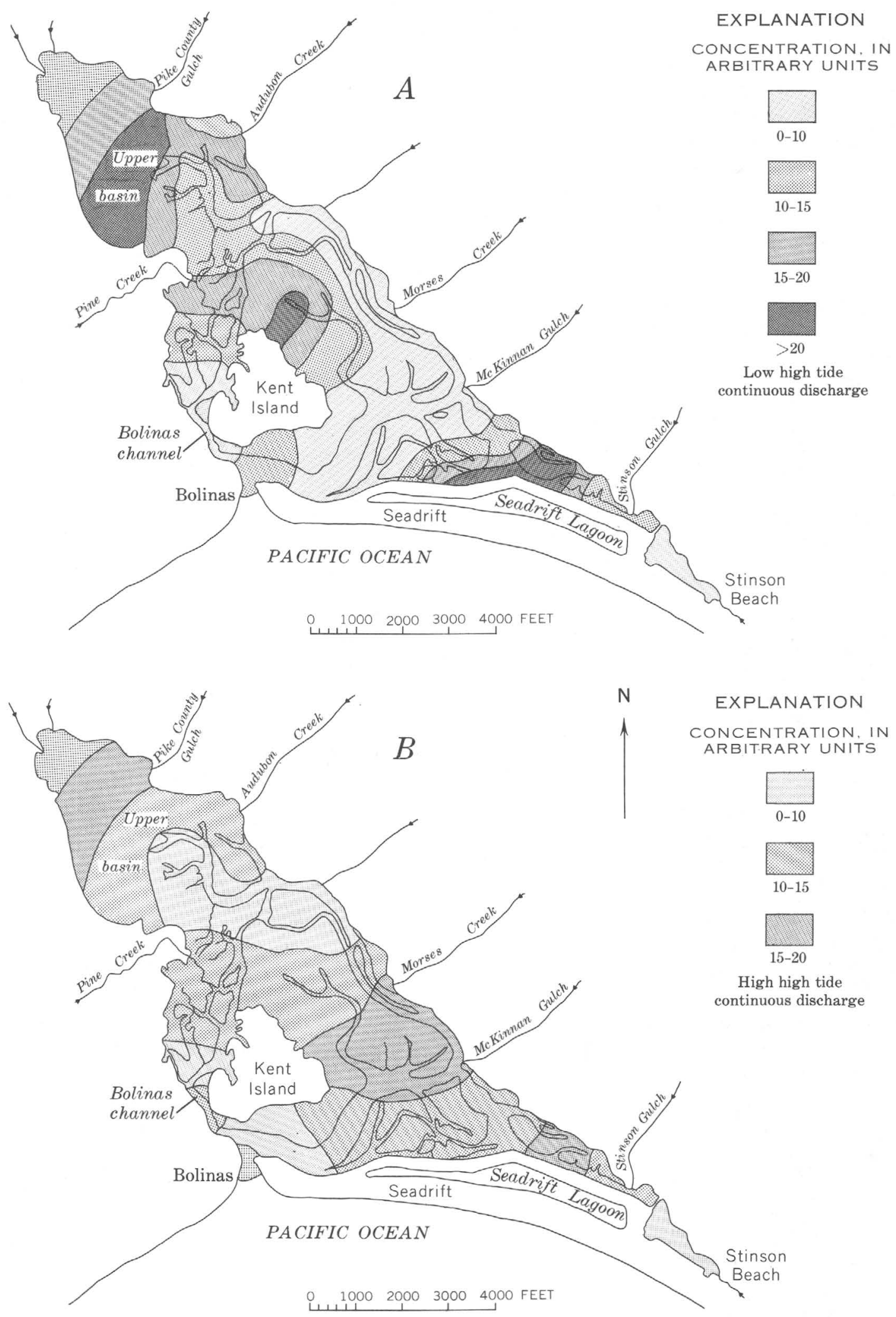

Figure 10.-Numerically predicted concentrations resulting from a constant-rate discharge at the lagoon mouth, after 10 repetitions of the tidal cycle of Nay 21-22, 1969. A, at the low high tide; $B$, at the high high tide. 

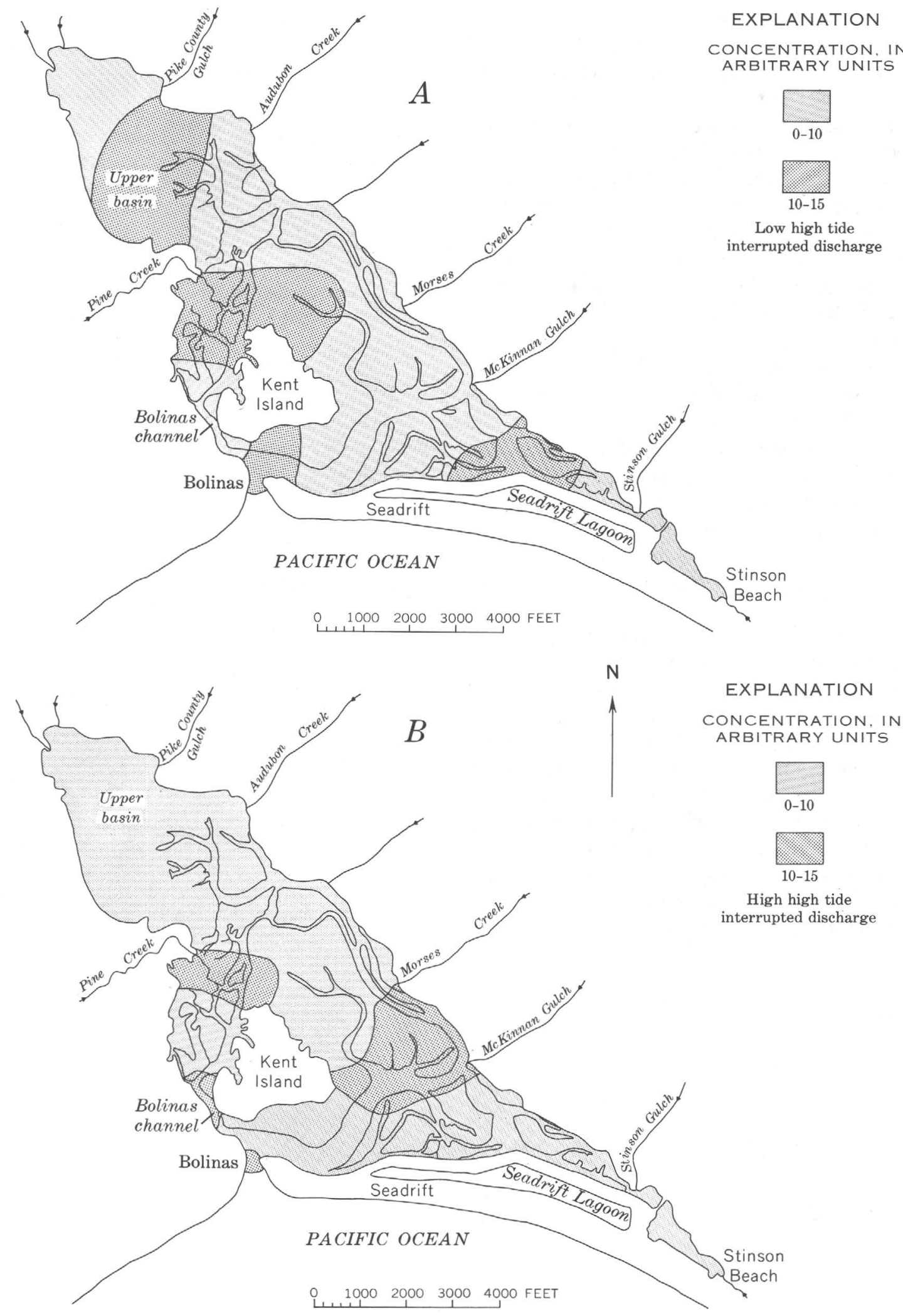

FIGURE 11.-Numerically predicted concentrations resulting from an interrupted constant-rate discharge at the lagoon mouth, after 10 repetitions of the tidal cycle of May 21-22, 1969. A, at the low high tide, if no pollutant is discharged during a 2-hour period at the low and high tides: $B$, at the high high tide, for the same conditions as in $A$. 
persion of the dye cloud followed the prediction of the numerical program. The program was also used to predict the distribution of a pollutant which is continuously discharged into the mouth of the lagoon at the location of the existing sewage outfall pipe. The prediction showed that at high tide, high concentrations of sewage would exist at the northernmost and southernmost ends of the lagoon, while lower concentrations would be found in the center section. The prediction, while not verified by a dye-tracer experiment, seemed to conform to visual and ecological observations of the areas of greatest pollution.

The numerical program was used to predict the distribution of concentration if sewage were released continuously at the location of the existing discharge pipe but withheld during a detention period of 2 hours at low tide. The concentrations predicted within the lagoon were significantly lower than if the sewage were released continuously without interruption.

The computer program developed in this study should be of value to pollution studies in other tidal embayments whose geometry has the same character as that of Bolinas Lagoon. The program is suited to embayments in which the geometry of flow changes significantly between high and low tide. The program is one dimensional in the sense that the embayment must be segmented into channels which are on dimensional, but these segments may be connected to form a two-dimensional embayment. Thus the program is capable of describing dispersion in a multibranched tidal inlet in which large expenses of mudflat are exposed at low tide but shallowly covered at high tide. The program should yield reasonably accurate predictions of the dispersion of a pollutant from either an instantaneous slug source or from a constant-rate injection.

\section{REFERENCES CITED}

Bowden, K. F., 1963, The mixing processes in a tidal estuary: Internat. Jour. Air and Water Pollution, v. 7, p. 343-356.

Elder, J. W., 1959, The dispersion of marked fluid in turbulent shear flow: Jour. Fluid Mechanics, v. 5, p. 544-560.

Fischer, H. B., 1967, The mechanics of dispersion in natural streams: Am. Soc. Civil Engineers Proc., Jour. Hydraulics Div., v. 93, no. HX6, p. 187-216.

- 1968, Methods for predicting dispersion coefficients in natural streams, with application to the Green and Duwamish Rivers, Washington: U.S. Geol. Survey Prof. Paper 582-A, $27 \mathrm{p}$.

Gustofson, J. F., 1968, Ecological study, Bolinas Lagoon, Marin County, California, report no. 2: Resources \& Ecology Projects, P.O. Box 87, Mill Valley, California, $45 \mathrm{p}$.

Harleman, D. R. F., 1964, The significance of longitudinal dispersion in the analysis of pollution in estuaries: Int. Water Pollution Research Conf., 2d, Tokyo, 1964, Proc., v. 1, p. 279-306.

Holley, E. A., Harleman, D. R. F., and Fischer, H. B., 1970, Dispersion in homogeneous estuary flow: Am. Soc. Civil Engineers, Proc., Jour. Hydranlics Div., v. 96, no. HY8, p. 1691-1709.

Lai, Chintu, 1967, Computation of transient flows in rivers and estuaries by the multiple-reach method of characteristics: U.S. Geol. Survey Prof. Paper 575-D, p. D273-D280.

Orlob, G. T., Selleck, R, Shubinski, R. P., Walsh, F., and Stann, E., 1968, Modeling of water quality behavior in an estuarial environment. Internat. Water Pollution Research Conf., 4th Prague, Proc., p, 845-855.

Pritchard, D. W., 1958, A study of flushing in the Delaware model: Tech. rept. 7 , The Chesapeake Bay Inst., Johns Hopkins Univ.

Ritter, J. R., 1969, Preliminary studies of sedimentation and hydrology in Bolinas Lagoon, Marin County, California: U.S. Geol. Survey open-file report, 68 p.

Taylor, G. I., 1954, The dispersion of matter in turbulent flow through a pipe: Royal soc. [London] Proc., ser. A, v. $223,6.446-468$.

Thomann, R. V., and Sobel, M. J., 1964, Estuarine water quality management and forecasting: Am. Soc. Civil Engineers Proc., Jour. Sanitary Eng. Div., v. 90, no. SA5, p. $9-36$. 
TABLES 1 AND 2 
[Identification of indices: IT $=$ number of the time step within the tidal cycle; ICYCLE $=$ number of the tidal cycle; $\mathrm{M}=$ number identifylng the segment; $N=$ volume element within the segment. Examples: $C(M, N)$ is the concentration of the Nth rolume element in the Mth segment $B(M, I T)$ is the width of the Mth segment during the IT th time step of any tidal cycle]

\section{Main program}

Reference No.

(see table 2)

Read input data:

For the program as a whole:

Identification of run (IDEN);

Number of segments (MMAX);

Number of time steps in one tidal cycle (ICYCLE);

Segment into which a continuous discharge of pollutant is to flow (MINPUT) ;

Amount of mass input per time step for continuous discharge (ADD) ;

Basic mass-transfer coefficient for diffusive step (E);

Decay factor (DIEOFF) ;

Position of continuous discharge within segment (XADD);

Program control information (IPRINT, JSTOP,NPASS1,NPASS2).

For each segment in turn:

110 Number of elements initially in segment (NMAX(M)) ;

Length of segment (XL(M));

Segments to which given segment is connected in landward direction (MA(M), MB(M), $\mathrm{MC}(\mathrm{M}))$;

Segment to which given segment is connected in seaward direction (MD(M));

Mean depth of segment at each time step throughout tidal cycle (H(M,IT));

Width of segment at each time step throughout tidal cycle $(\mathrm{B}(\mathrm{M}, \mathrm{IT}))$;

Initial concentration of each element in segment $(\mathrm{C}(\mathrm{M}, \mathrm{N}))$.

$$
\downarrow
$$

130 Compute initial volume of each element of each segment by dividing total segment volume by number of elements initially in segment.

$$
\downarrow
$$

Read volume of fresh-water discharge per time step into those segments receiving a fresh-water discharge, if any.

$$
\downarrow
$$

200 Begin a time step. Increment IT (time-step index) by 1. If IT becomes greater than the number of steps in a tidal cycle (ICYCLE), reset IT to one (begin the next tidal cycle). At the beginning of each tidal cycle, increment ICYCLE by 1. When ICYCLE becomes greater than JSTOP, stop.

Executive subroutine MAP for each segment in turn, beginning with segment 1 and continuing through segment MMAX. MAP computes the volume transferred into or out of each segment during the time step and the concentration of pollutant in each volume. 
TABLE 1.-Annotated flow chart of the computer program-Continued

Main program-Continued

Reference No.

(see table 2)

212 During the first tidal cycle only, print the volume transferred across the landward end of each segment $(\mathrm{QO}(\mathrm{M}))$, the volume transferred across the seaward end $(\mathrm{QI}(\mathrm{M}))$, and the average distance traveled by a water particle within the segment (VEL $(M))$.

220 Execute subroutine BRANCH for each segment in turn. BRANCH adds or subtracts volume elements from the ends of each segment, according to the inflow or outflow calculated by MAP. It also calculates the concentrations of newly formed volume elements.

$$
\downarrow
$$

250 Execute subroutine DIFUSE for each segment in turn. DIFUSE carries out mass transfer between volume elements within each segment, as described in the text in the section "Diffusive Step." It also accomplishes the reduction of volume elements within a segment when this is required. DIFUSE prints the concentrations and locations of volume elements when requested by the program contro] information.

Add the pollutant mass given as ADD to the volume element selected by MINPUT and XADD. This simulates a continuous injection at a fixed location. For simulation of a slug injection ADD is set equal to zero.

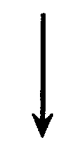

260 Reduce the concentration of each volume element by the factor given as DIEOFF to simulate a first-order decay process.

Return to the beginning of the time step.

\section{Subroutine MAP}

70 Compute the volume transported through the landward end of the segment $(Q O(M))$ by summing the volume transported through the seaward ends of the segments connected on the landward side and the fresh-water discharge if any, by the equation

$$
\mathrm{QO}(\mathrm{M})=\mathrm{QI}(\mathbf{M} 1)+\mathrm{QI}(\mathbf{M} 2)+\mathrm{QI}(\mathrm{M} 3) \text {; }
$$

M1, M2, and M3 are the landward-connected segments, or in the case of a fresh-water discharge QI(M3) is a fresh-water discharge stated in the main program. 
TABLE 1.-Annotated flow chart of the computer program-Continued

Subroutine MAP-Continued

Reference No. (see table 2)

80 Compute the volume transported through the seaward end of the segment (QI(M)) by equation 1 .

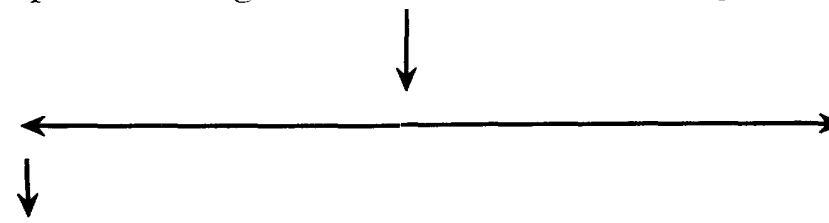

90 If the volume transported through either end of the segment is greater than the volume contained in the segment, the program will not operate. Print inflow, outflow, identification, and stop.

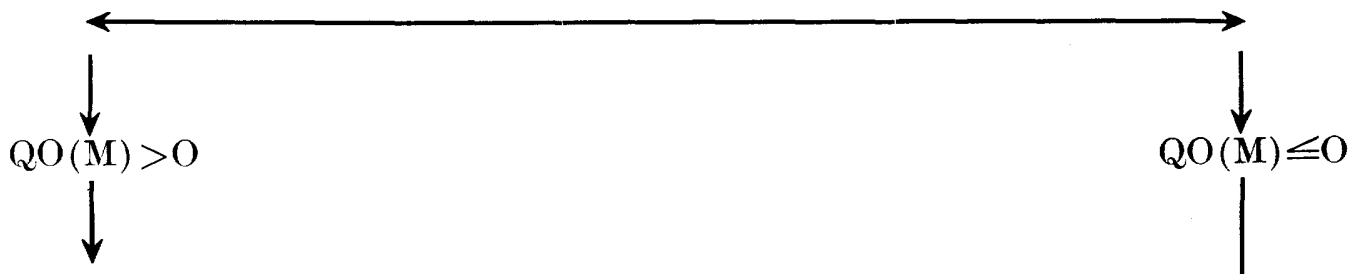

135 If flow is out of the landward end of the segment, compute the concentration of the outgoing volume by equation 4.
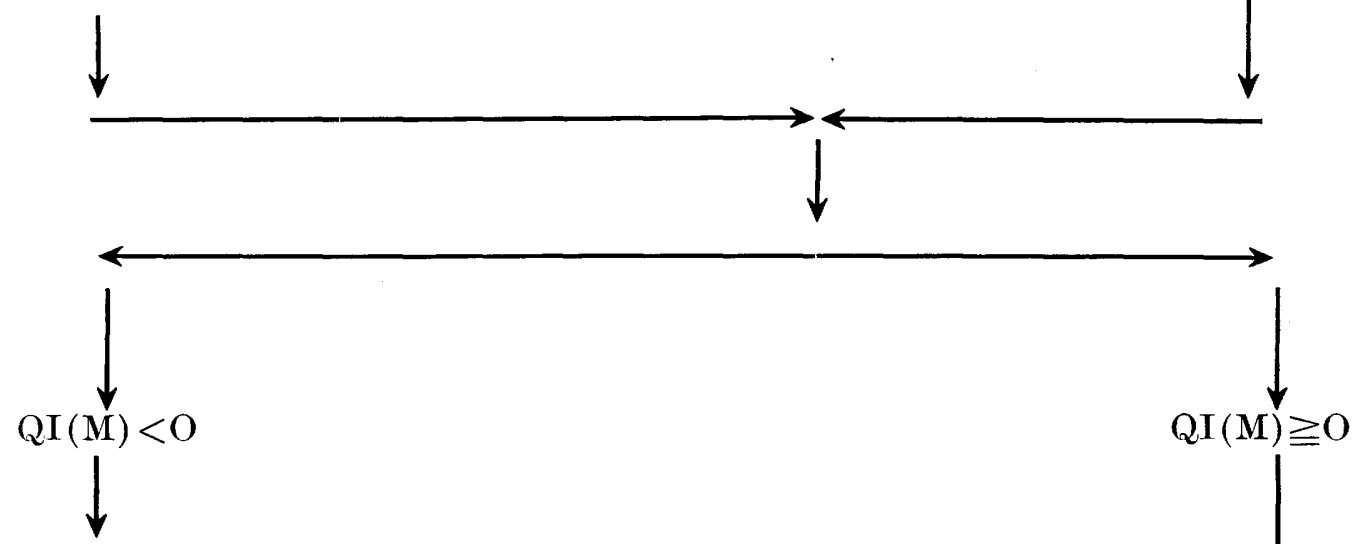

245 If flow is out of the seaward end of the segment, compute the concentration of the outgoing volume by equation 4 .

300 Return to the main program. The main program increments the segment index, M, by 1 and re-executes subroutine MAP until all segments are complete.

\section{Subroutine BRANCH}

Initiate for each segment in turn from the main program. 
TABLE 1.-Annotated flow chart of the computer program-Continued

Subroutine BRANCH-Continued

Reference No.

(see table 2)

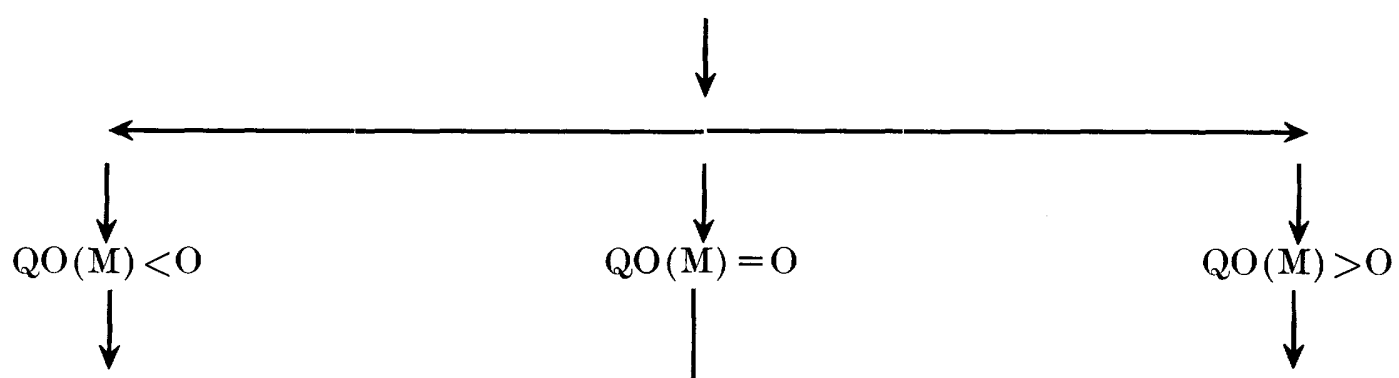

$120 / 230$ If flow is into the landward end, create a new $\mathrm{V}(\mathrm{M}, 1)$ and compute $\mathrm{C}(\mathrm{M}, 1)$ by proportioning the concentrations of the inflowing volumes. Increase the identifying index of each volume element previously in the segment by 1 , that is, $\mathrm{V}(\mathrm{M}, 1)$ becomes $\mathrm{V}(\mathrm{M}, 2)$, and so forth.

If flow is out of the landward end, reduce $\mathrm{V}(\mathrm{M}, 1)$ by the amount of the outward flow. If $\mathrm{V}(\mathrm{M}, 1)$, is reduced to zero, reduce $\mathrm{V}(\mathbf{M}, 2)$ by the remainder, and reduce the identifying index of each element by 1 ; that is, $\mathrm{V}(\mathrm{M}, 2)$ becomes $\mathrm{V}(\mathrm{M}, 1)$, and so forth. If $\mathrm{V}(\mathrm{M}, 2)$ is reduced to zero, reduce $V(M, 3)$ by the remainder, and let $\mathrm{V}(\mathbf{M}, 3)$ become $\mathrm{V}(\mathbf{M}, \mathbf{1})$, and so forth.

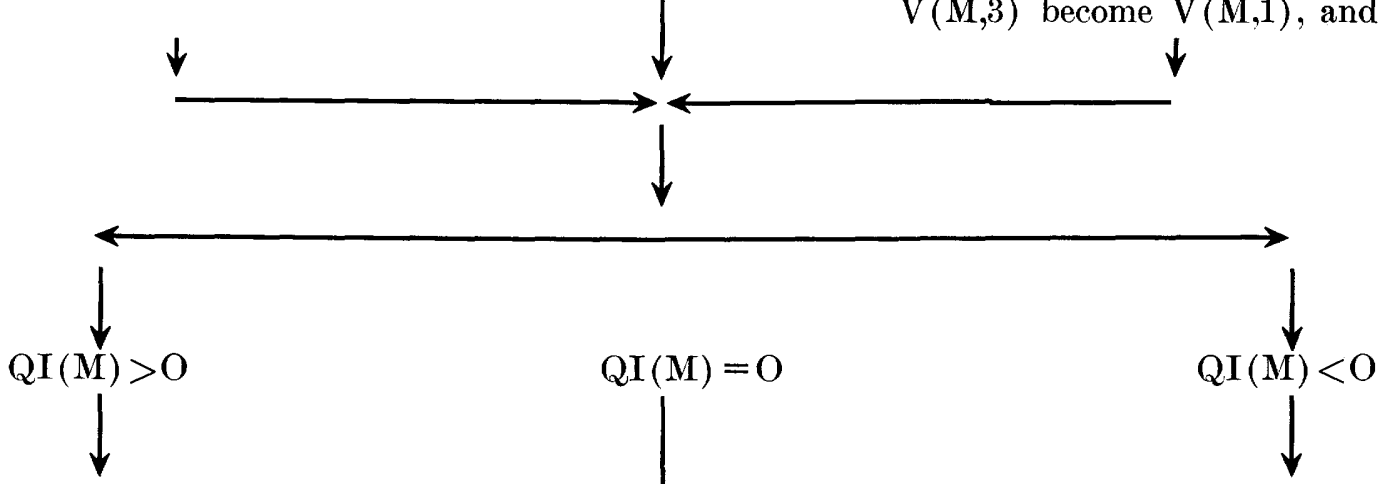

$500 / 420$ If flow is into the seaward end of the segment, create a new volume element, V(M,$\mathrm{N}+1$ ), whose volume equals the inflow and whose concentration, $\mathrm{C}(\mathrm{M}, \mathrm{N}+1)$, is that calculated for the inflow by MAP.

If flow is out of the seaward end, reduce $\mathrm{V}(\mathrm{M}, \mathrm{N})$ by the amount of the outward flow. If $\mathrm{V}(\mathrm{M}, \mathrm{N})$ is reduced to zero, reduce $\mathrm{V}(\mathrm{M}, \mathrm{N}-1)$ by the remainder, and reduce the number of volume elements in the segment by 1 . If $\mathrm{V}(\mathrm{M}, \mathrm{N}-1)$ is reduced to zero, reduce $\mathrm{V}(\mathrm{M}, \mathrm{N}-2)$ by the remainder, and so forth.

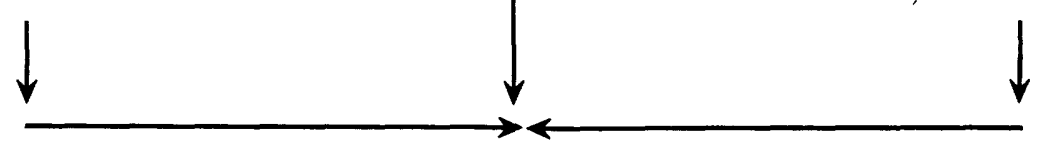

600 Return to the main program. The main program increments the segment index, M, by 1 and re-executes subroutine BRANCH until all segments are complete.

Subroutine DIFUSE

Initiate from the main program for each segment in turn.

100 Compute the length $(\mathrm{XE}(\mathrm{N})$ of each volume element by dividing the volume $(\mathrm{V}(\mathrm{M}, \mathrm{N}))$ by the cross-sectional area of the segment $(\mathrm{BH}(\mathrm{M}, \mathrm{IT}))$. 
110 Compute the distance from the landward end of the segment to the center of each volume element $(\mathrm{X}(\mathrm{N}))$.

If the combined length of the two endmost elements on either end of the segment is less than the average length of one element, that is less than the length of the segment divided by the number of elements within the segment, combine the two endmost elements into one whose concentration is the weighted average of the two being combined. Return to the beginning of this step.

$$
\downarrow
$$

Compute the mass transfer between adjacent elements, beginning with element pair (M,2), (M,1) and continuing to pair $(\mathrm{M}, \mathrm{N}),(\mathrm{M}, \mathrm{N}-1)$. For each pair, carry out the following steps:

1. Determine which of the two elements is shorter.

2. Using the length of the shorter element, compute the adjusted mass-transfer coefficient by equation 7 .

3. Compute the mass transfer.

4. Adjust the concentration in each element to accomplish the mass transfer.

260 If called for by the program control information, print the location and concentration of each volume element.

290 If the element being considered is one into which a continuous injection is to be put, compute the number of the element whose concentration is to be increased.

$$
\downarrow
$$

Return to the main program. The main program increments the segment index, M, by 1 and reexecutes subroutine DIFUSE until all segments are complete. 
PROGRAM LAGCON(INPUT, OUTPUT)

DIMENSION MA (12), MB(12), MC (12), MD(12), VEL (12), IDEN (13)

COMMON/A/NMAX $(12), X L(12), B(12,125), H(12,125), V(12,50), C(12,50)$,

$1 Q I(25), 00(20), B H(12,125), C O(21), C I(25), J P, N O(12), N I(12)$,

2IPRINT, I T, I TPI, EFOR, EBACK, ICYCLE

COMMON/B/NADD, XADD

COMMON/C/MINPUT

DATA NMAX (1)/O/

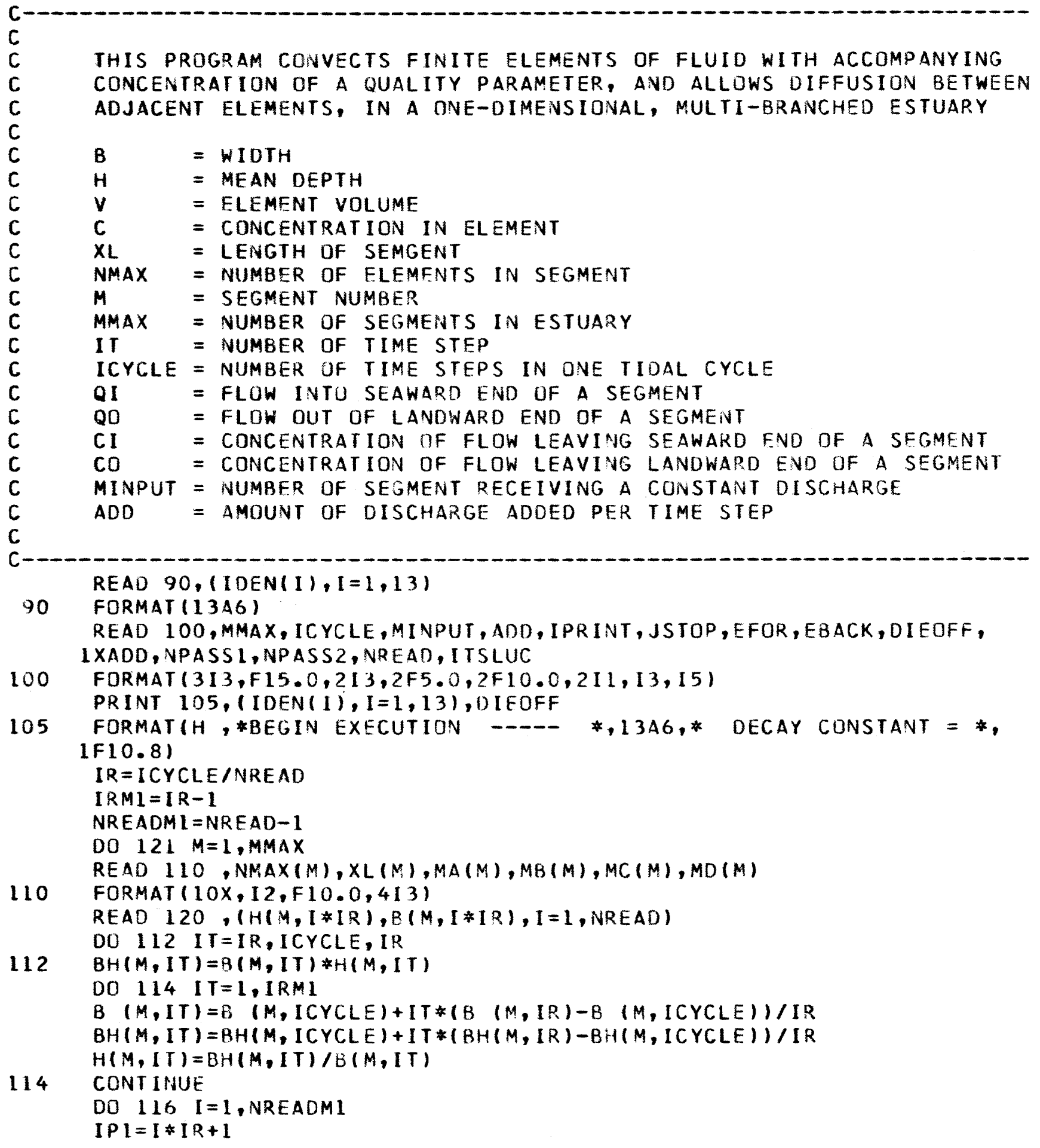


$I E N D=I * I R+I R M I$

DO 116 IT $=$ IPI, IEND

$B(M, I T)=B(M, I * I R)+(I T-I * I R) *(B \quad(M, I * I R+I R)-B(M, I * I R)) / I R$

$B H(M, I T)=B H(M, I * I R)+(I T-I * I R) *(B H(M, I * I R+I R)-B H(M, I * I R)) / I R$ $H(M, I T)=B H(M, I T) / B(M, I T)$

CONTINUE

FORMAT (1OF8.0)

CONTINUE

IF(NPASSI.NE.0) GO TO 128

DO126 $M=1$, MMAX

PRINT $122, M, X L(M), M A(M), M B(M), M C(M), M D(M)$

122 FORMATIIHO,*BRANCH *,12,*, LENGTH*,F12.2,*, LANDWARD BRANCHES *,

$13(12, \mathrm{H}, \mathrm{l}), *$ SEAWARD BRANCH *, 12,1$)$

PRINT $124,(H(M, I T), B(M, I T), I T=I R, I C Y C L E, I R)$

124

126

128

FORMAT $(6(2 X, F 6.2, F 10.1,4 X))$

CONTINUE

CONT INUE

DO $140 \quad M=1$, MMAX

$V O L=B H(M, 1) * X L(M)$

$V(M, 1)=V O L / N M A X(M)$

$N T=N M A X(M)$

DO $130 \mathrm{~N}=2, \mathrm{NT}$

130

$V(M, N)=V(M, 1)$

140 CONTINUE

DO $160 \mathrm{M}=1$, MMAX

$N T=N M A X(M)$

READ $120,(C(M, N), N=1, N T)$

160

CONTINUE

JCYCLE $=1$

I $\mathrm{T}=0$

DO $165 M=1,21$

$\operatorname{CO}(M)=0$.

$165 \quad C I(M)=0$.

$198 \mathrm{JP}=0$

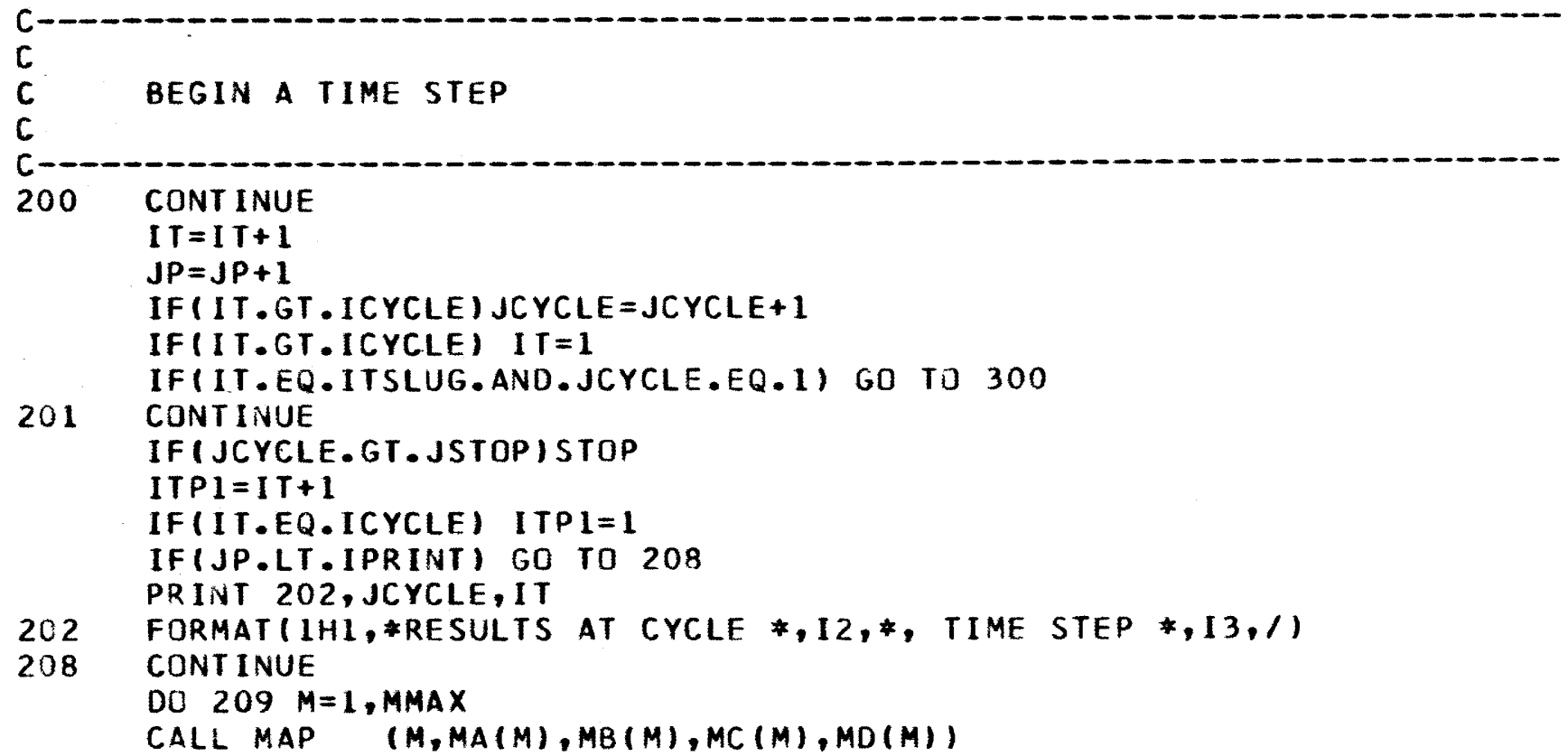


METHOD FOR PREDICTING POLLUTAN' DISPERSION IN BOLINAS LAGOON, CALIFORNIA

TABLE 2.-Fortran listing of computer program for $C D C 6400$ computer-Continued

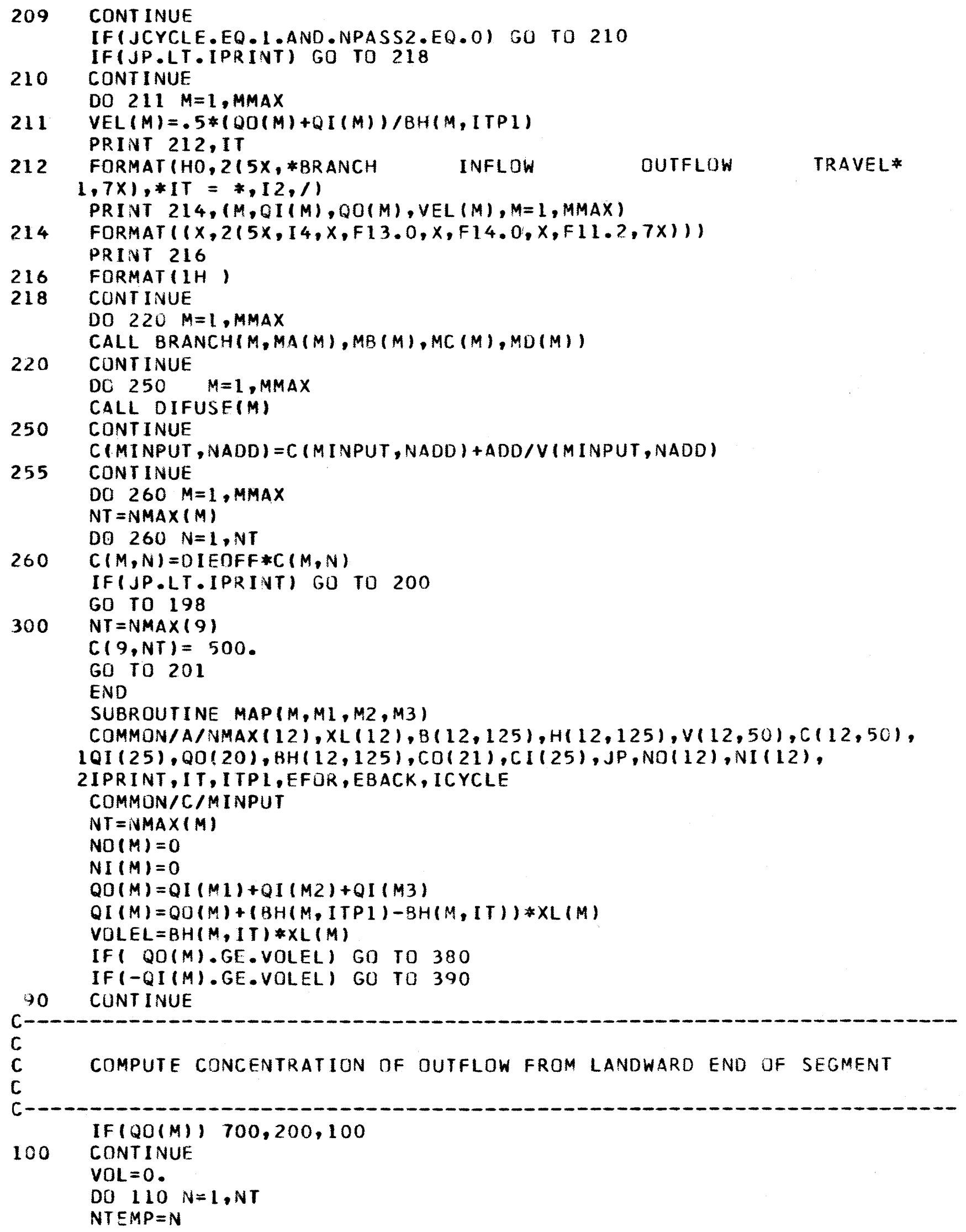




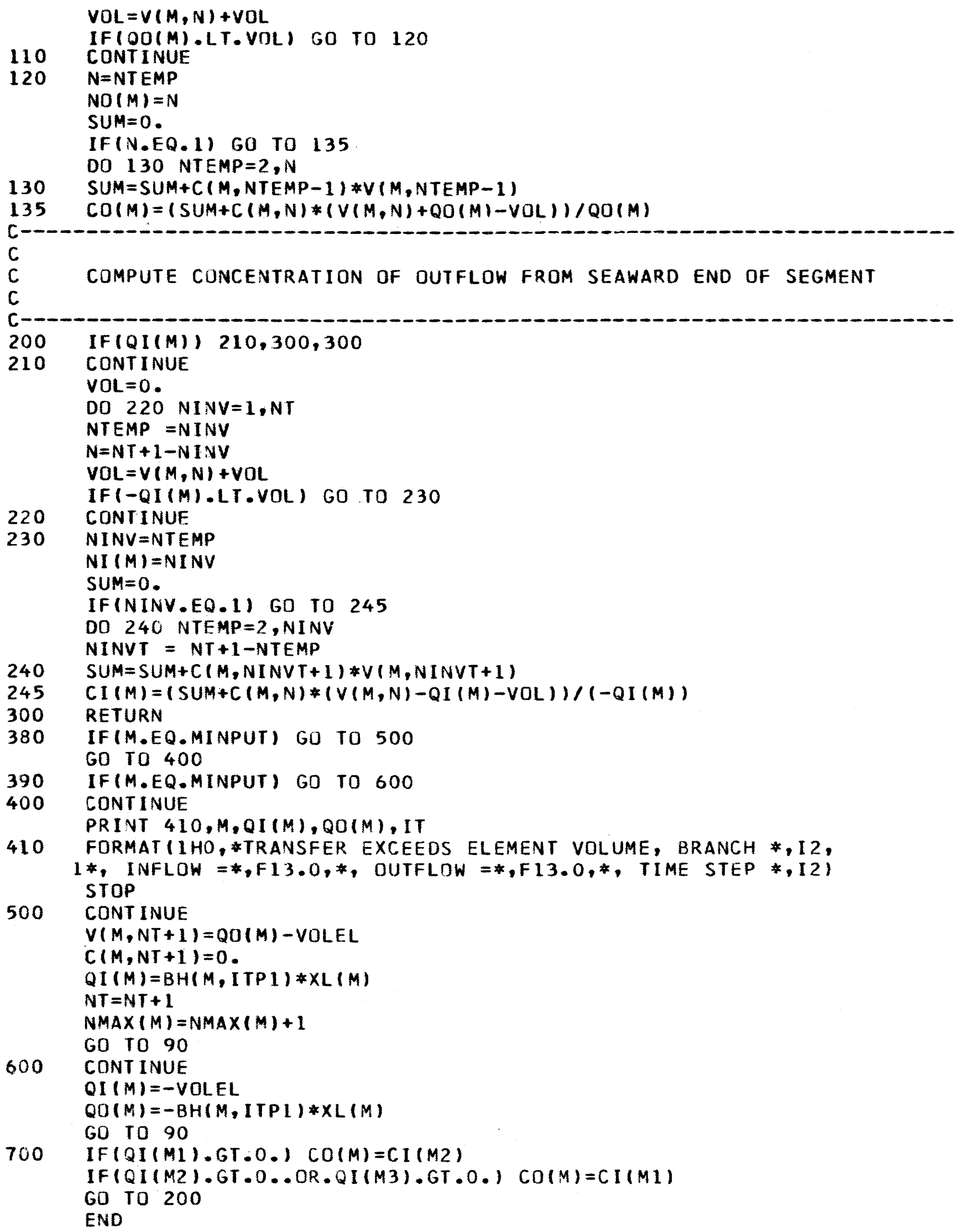


METHOD FOR PREDICTING POLLUTANT DIS PERSION IN BOLINAS LAGOON, CALIFORNIA

TABLE 2.-Fortran listing of computer program for CDC 6400 computer-Continued

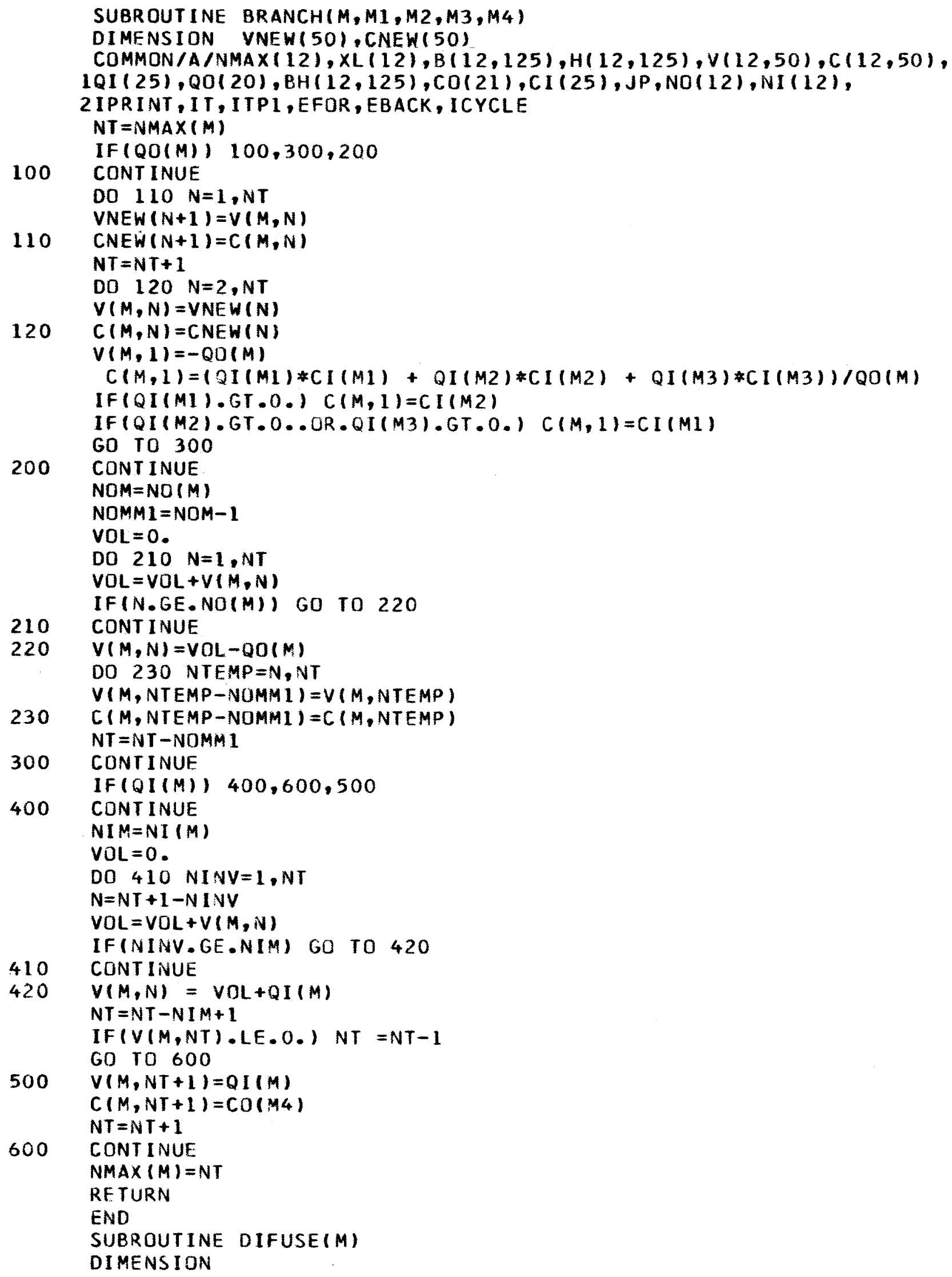




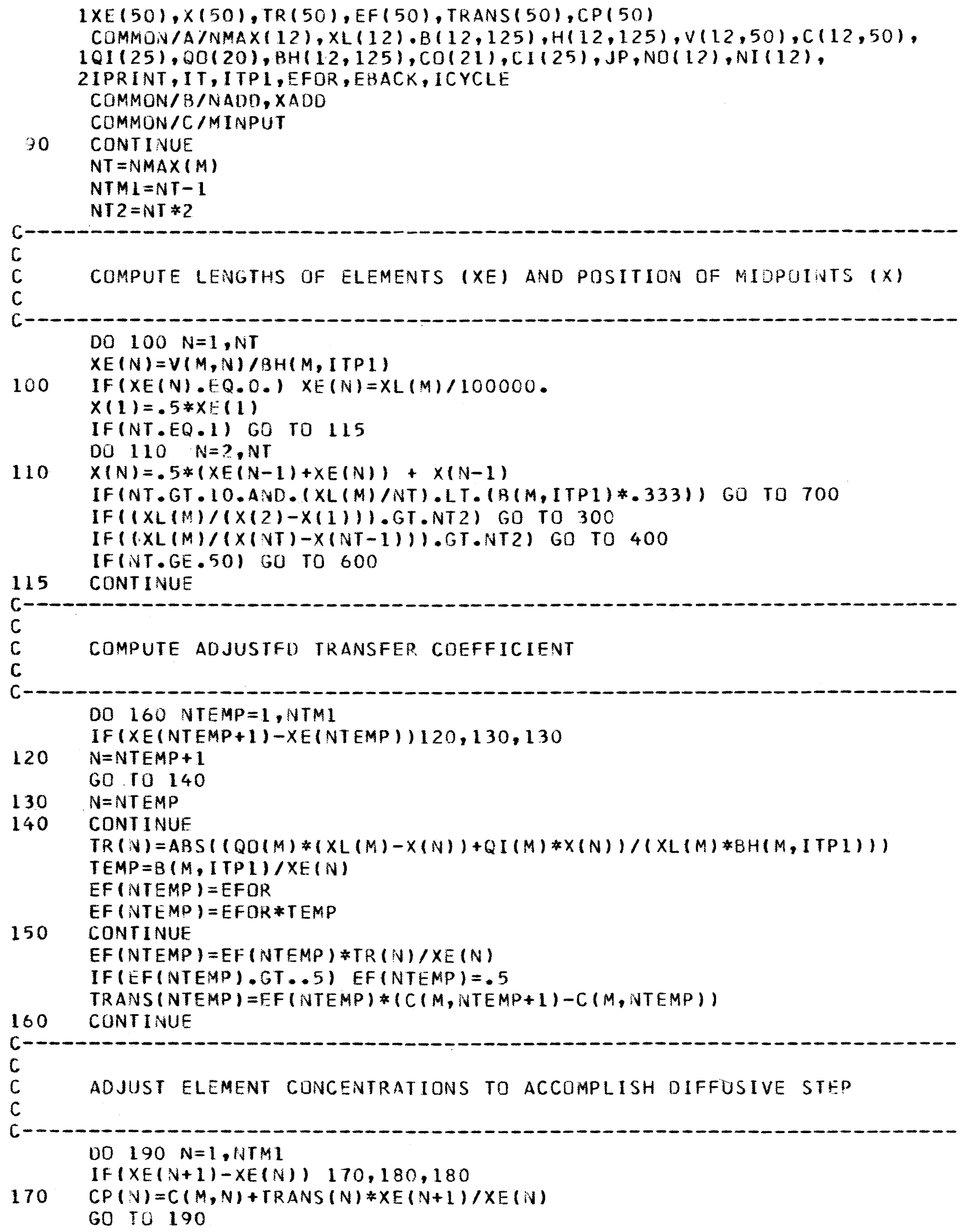


TABLE 2.-Fartran listing of computer program for $C D C 6400$ computer-Continued

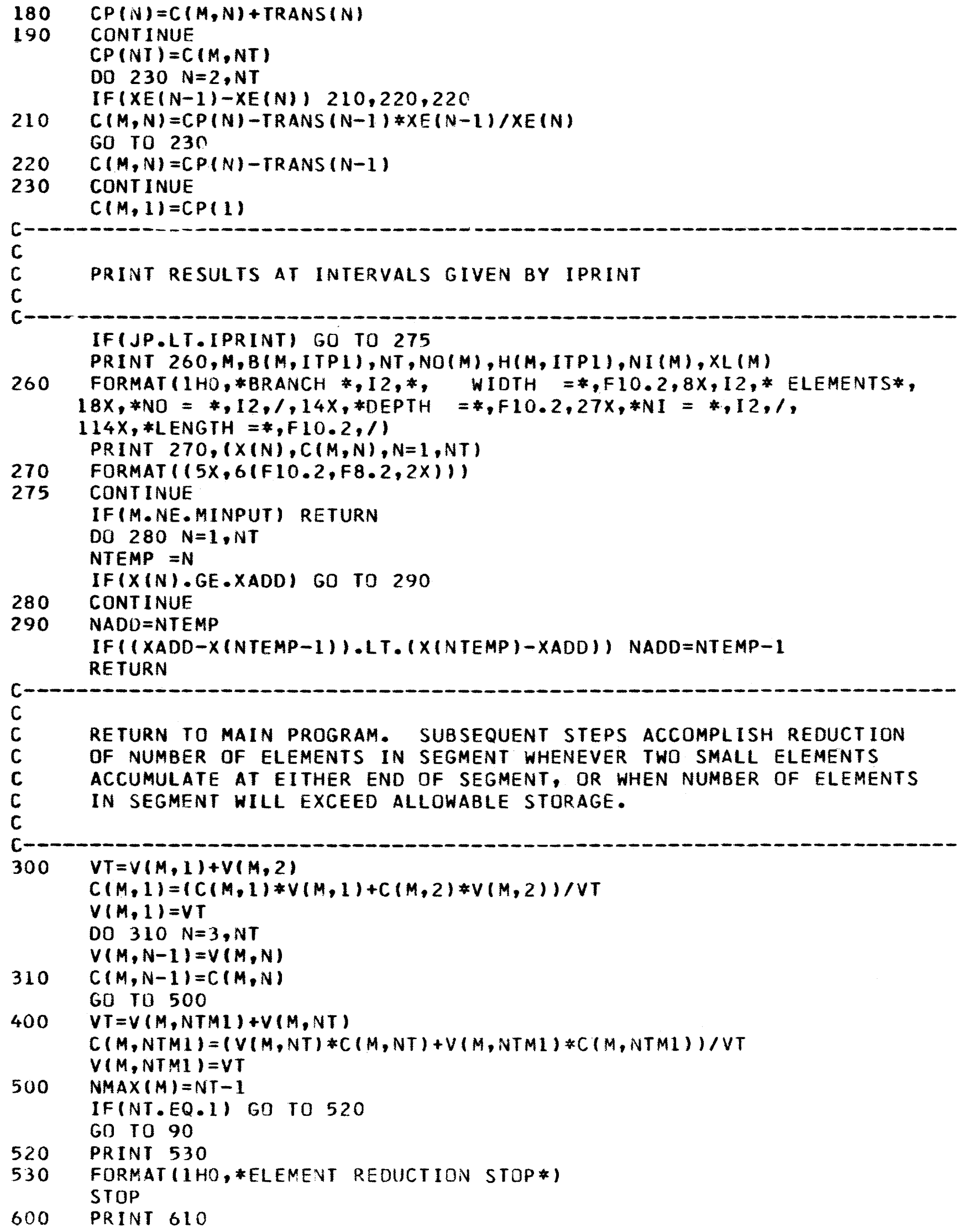




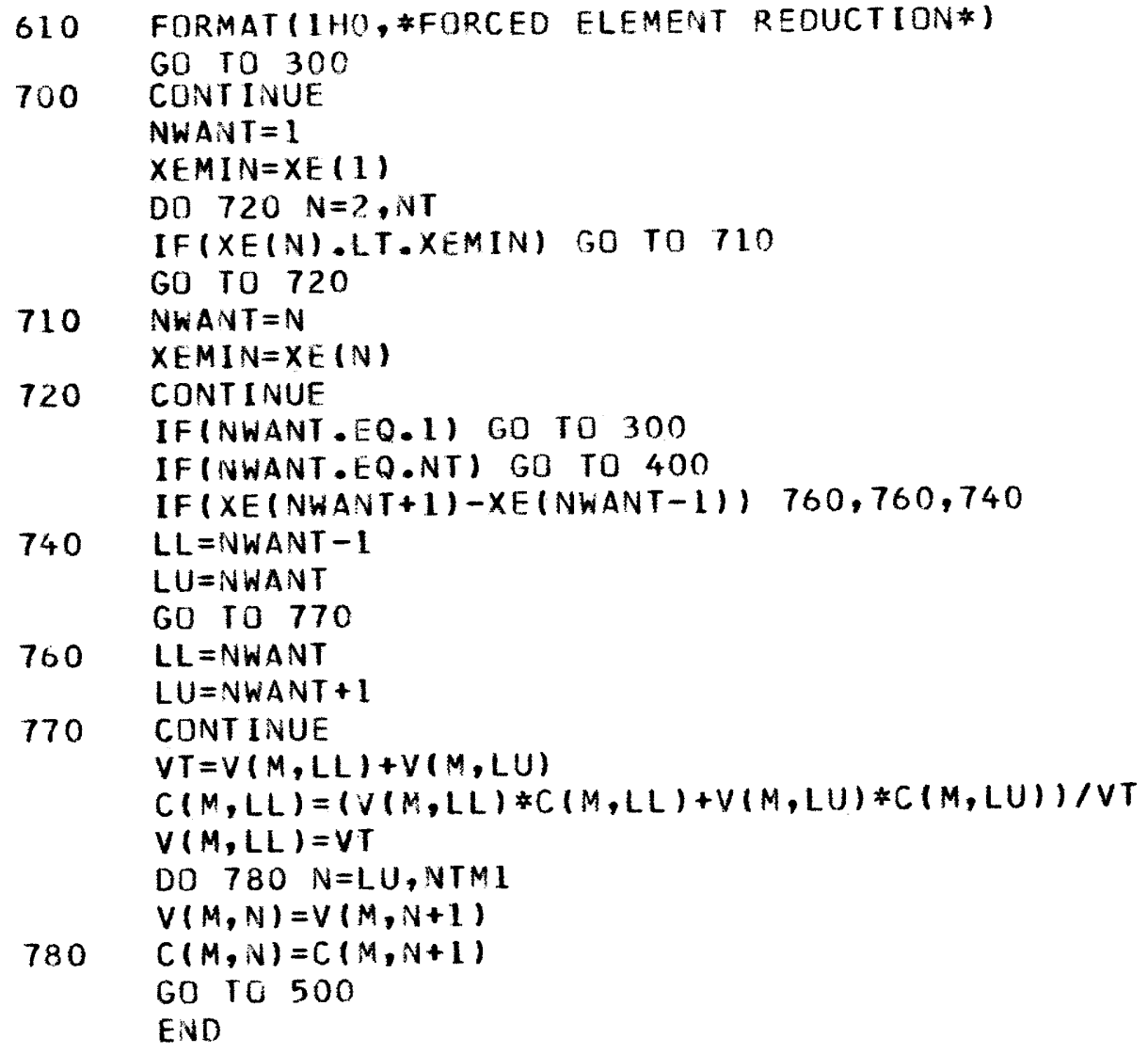

